\title{
Optimal (Partial) Group Liability in Microfinance
}

\section{Lending*}

\author{
Treb Allen ${ }^{\dagger}$ \\ Northwestern University and NBER
}

First version: July 2009

This version: July 2015

\begin{abstract}
This paper develops a model of group borrowing that incorporates partial group liability, where borrowers are penalized if their group members default but are not held responsible for the entirety of the failed loan. The model illustrates a trade-off of group liability lending: while higher levels of group liability increase within group risk-sharing, if liability is too high, borrowers strategically default. The model predicts the existence of an optimal partial liability that maximizes transfers between group members while avoiding strategic default. Consistent with this prediction, loan officers from a large microfinance institution in southern Mexico who rarely allow one group member to repay while the other defaults achieve substantially lower default rates than loan officers for whom the practice is commonplace or for those for whom it has never occurred. Structural estimation using repayment data suggests that while a partial liability below full liability may reduce default rates, the incidence of strategic default is rare.
\end{abstract}

Keywords: microfinance, group lending, liability, strategic default, Mexico

JEL Classification: G11, G21, O12, O16

*I would like to thank Beatriz Armendariz, Dean Karlan, Maitreesh Ghatak, Tim Guinnane, Mark Rosenzweig, and Chris Udry, as well as seminar participants at Yale University, the London School of Economics, the University of Cambridge, the World Bank and three anonymous referees. I would also like to thank the staff at Grameen Trust Chiapas and Innovations for Poverty Action for their assistance with the data. This material is based upon work supported under a National Science Foundation Graduate Research Fellowship. All errors are my own.

${ }^{\dagger}$ Department of Economics, Northwestern Unversity, Evanston, IL 60201. Email: treb.allen@northwestern.edu. 


\section{Introduction}

The advent of group liability - where multiple borrowers are jointly responsible for the repayment of their loans - has been identified as an important factor in the expansion of access to credit in the developing world (Morduch, 1999; Armendariz and Morduch, 2010). Group liability helps overcome information asymmetries between borrowers and lenders and incentivizes risk sharing within borrowing groups (Ghatak and Guinnane, 1999). At the same time, however, group liability may induce borrowers to strategically default when their group members default, increasing default rates (Besley and Coate, 1995). While empirical evidence of the effect of group liability on repayment is scant, ${ }^{1}$ determining the optimal group liability remains a pressing concern for lenders. For example, to avoid strategic defaults, Grameen Bank transitioned from its traditional full liability group loans to individual liability loans in 2002 (Yunus, 2002; Dowla and Barua, 2006).

The goal of this paper is to see if a partial group liability - where borrowers are penalized if their group members default but are not held responsible for the entirety of the failed loan - can lead to lower default rates than either individual liability of full group liability. ${ }^{2}$ To do so, I first develop a simple model of group borrowing that highlights the tradeoffs associated with group liability; while higher group liability provides an incentive for group members to share risk with each other, too high group liability can incentivize strategic default. The model implies that intra-group risk sharing is maximized and strategic default avoided when the group liability is equal to the present discounted value of repaying the loan and remaining eligible to borrow in the future. I then use administrative data from a large microfinance institution to show that loan officers who appear to be enforcing high (but not full) partial group liability achieve substantially lower default rates than those who either appear to be enforcing full group liability or those who appear to be enforcing lower group

\footnotetext{
${ }^{1}$ One notable exception is Gine and Karlan (2011), who experimentally remove the group liability provision in existing borrowing groups. They find no evidence of increased default rates but do not consider the possibility of partial group liability.

${ }^{2}$ Rai and Sjöström (2004) and Bhole and Ogden (2010) also show that relaxing full group liability can theoretically reduce default rates; I discuss how my model relates to theirs below.
} 
liability. Finally, I structurally estimate the model and find that default rates are minimized at a partial group liability below full liability.

The borrowing model is based on a repeated game framework where borrowers repay their current loan in order to remain eligible to borrow in the future. Borrowers receive stochastic and potentially correlated returns to borrowing, which they then may transfer to their group member. The lender can penalize borrowers if their group member fails to repay and can refuse to lend to defaulting borrowers in the future but cannot directly penalized defaulters. The model has two implications. First, if the penalty for having a group member default exceeds the present discounted value of repaying the loan and remaining eligible to borrow in the future ("the value of future borrowing"), then a borrower will find it optimal to strategically default. Second, the transfer a borrower is willing to make is bounded above by the cost incurred by letting her group member default, which is the lesser of the group liability penalty and the value of future borrowing. As a result, the optimal group liability is the value of future borrowing; any less liability reduces within-group risk sharing, and any greater liability induces strategic default. I show that this optimal group liability minimizes default rates and maximizes the value of borrowing.

Because the repayment behavior of group members becomes more correlated the greater the amount of risk-sharing, the model implies that the probability of a borrower repaying conditional on her group member defaulting declines as the group liability approaches the optimal group liability. Once the group liability exceeds the optimal group liability, however, strategic default becomes optimal so the probability of one group member repaying when another defaults is zero. Using administrative data from a large microfinance institution (MFI) in southern Mexico, I test this prediction empirically. In qualitative interviews with the administrators of the MFI, it was emphasized that loan officers had substantial latitude in determining the group liability that he or she enforced. I use this variation across loan officers to show that loan officers for whom the probability of default conditional on a group member defaulting amongst the subset of two-person borrowing groups achieved lower default 
rates in all other borrowing groups than loan officers in their same MFI branch for whom this conditional probability was either higher or zero. By conditioning on the total default rate of a loan officer in two-person borrowing groups, I ensure that the estimated differences in outof-sample default rates come from the particular combination of defaults within a borrowing group rather the total number of defaults, mitigating the concerns that the results are being driven by differences in the quality of loan officers.

Having shown that loan officers who appear to be maximizing within-group risk sharing without incentivizing strategic default achieve the lowest default rates, I structurally estimate the model in order to estimate the optimal group liability. By relying on the variation across loan officers in the liability enforced and the assumption that loan officers were randomly assigned to borrowers, the structural estimates recover both the unobserved group liability enforced by each loan officer as well as the parameters governing the distribution of returns to borrowing. The structural estimates suggest high but variable returns to borrowing that are negatively correlated between group members. The optimal group liability is estimated to be $98 \%$ the repayment cost of the loan; i.e. default rates are minimized when borrowers are required to repay almost the full amount of the loan when a group member defaults. This estimate is statistically significantly different from full liability (at the one-sided 10\% level, but not at the one-sided 5\% level) and individual liability (at the one-sided 5\% level), suggesting that partial group liability may reduce the incidence of default. However, the estimated reduction in default is modest: moving all loan officers to the optimal group liability is estimated to reduce default rates from $3.61 \%$ to $3.51 \%$. To put this in context, if all loan officers in the sample enforced the optimal group liability, the model predicts there would be about ten fewer defaults in the sample of 7,844 loans. Furthermore, the estimated probability of strategic default is negligible, suggesting that full liability yields nearly as small default rates as the optimal liability.

This paper follows a long literature examining the tradeoffs of group liability in lending. Stiglitz (1990) shows that group liability can induce safer project choice through peer mon- 
itoring but at the cost of increasing the risk undertaken by the borrower. Ghatak (1999) shows that group liability induces assortative matching in group formation, lowering the effective borrowing costs of good borrowers and reducing default rates. In both papers, the authors show that the optimal group liability is strictly greater than individual liability. Besley and Coate (1995), in contrast, show that individual liability lending may perform better than group liability lending because of the possibility of strategic default. Rai and Sjöström (2004) analyze the role group liability plays in incentivizing within-group risk sharing using a mechanism-design framework and argue that an efficient lending scheme requires borrowers to be able to report their group members to the MFI for withholding output (i.e. "cross-report"). Bhole and Ogden (2010) show that a flexible joint liability contract where the amount a repaying borrower is penalized for her group member's default is optimally determined implies that borrower welfare will be strictly higher with group liability than partial liability. More recently, Baland, Somanathan, and Wahhaj (2013) show that the relative benefits of group liability to individual liability depends importantly on the wealth of the borrower, while de Quidt, Fetzer, and Ghatak (2013) show that in the presence of social capital, implicit joint liability loans can be sustained even without joint liability explicitly enforced by the lender. ${ }^{3}$

The model presented in this paper most closely resembles those Besley and Coate (1995), Rai and Sjöström (2004), and Bhole and Ogden (2010). Like Besley and Coate (1995), the model presented below abstracts from project choice and group selection but allows for strategic default; however, the model here allows for endogenous within-group risk sharing, where, like Rai and Sjöström (2004), borrowers make transfers to avoid incurring penalties from the bank. Like Bhole and Ogden (2010), the incentive for borrowers to repay arises from the promise of remaining eligible for future loans; as a result, as in Bhole and Ogden (2010), the optimal group liability penalty depends importantly on how much borrowers

\footnotetext{
${ }^{3}$ Other papers examining the role of group liability in microfinance lending include Banerjee, Besley, and Guinnane (1994); Armendariz de Aghion (1999); Ghatak (2001); Madajewicz (2004); Rai and Sjöström (2004); Chowdhury (2005); and Gangopadhyay, Ghatak, and Lensink (2005).
} 
value remaining eligible to borrow. Unlike Rai and Sjöström (2004) or Bhole and Ogden (2010), I characterize the equilibrium repayment decisions for an arbitrary joint probability distribution of returns to borrowing between two borrowers, which allows the model to be sufficiently flexible to be used quantitatively in conjunction with repayment data.

While the theory presented is novel in certain respects, the main contribution of this paper is to bridge the gap between theory and empirics, much in the spirit suggested by Ahlin and Townsend (2007). The empirical literature examining the effect of group liability on repayments is small but growing (Madajewicz, 2003; Gine and Karlan, 2011; Giné, Krishnaswamy, and Ponce, 2011). Instead of relying on natural or field experiments as sources of identification, however, this paper is the first attempt (that I am aware) to use a structural approach to identify model parameters from the observed combinations of repayment and default within a borrowing group. Given the modest data requirements necessary to implement the estimation procedure, the paper provides a methodology that can be used to determine the optimal degree of group liability in other contexts.

More broadly, this paper contributes to the large literature examining the various factors that affect the efficiency of microfinance lending. A (non-exhaustive) list of these factors includes the role of dynamic incentives (e.g. Tedeschi (2006)), social interactions (e.g. Feigenberg, Field, and Pande (2011)), market structure (e.g. de Quidt, Fetzer, and Ghatak (2012)), investment choice (e.g. Fischer (2012)), group size (e.g. Abbink, Irlenbusch, and Renner (2006)), repayment frequency (e.g. Fischer and Ghatak (2010)) and lender monitoring (e.g. Conning (1999)) .

The rest of the paper is organized as follows. The model is presented in the next section. Section 3 describes the empirical context and data. Section 4 provides empirical evidence that partial liability is associated with lower default rates than either full or individual liability. Section 5 structurally estimates the model to determine the optimal group liability. Finally, section 6 concludes. 


\section{The model}

In this section, I introduce a simple model of group liability borrowing. Borrowing is modeled as a repeated game in which every period borrowers have an incentive to default but continue to repay in order to remain eligible for future loans. Partial group liability is modeled as a monetary penalty the lender imposes on a borrower if her group member fails to repay. The basic intuition of the role played by partial group liability is simple: as the penalty increases, borrowers will be willing to transfer more money to their group member to allow their group member to repay; however, if the penalty becomes too high, then borrowers prefer to strategically default when their group member fails to repay rather than incur the penalty. I then show that the optimal group liability that minimizes default rates and maximizes welfare is the largest liability that does not incentivize strategic default.

\subsection{Setup}

Borrowing groups are composed of two identical infinitely-lived and risk-neutral individuals. The two individuals maximize their present discounted value of borrowing given their discount rate $\beta<1$. For simplicity, I assume the only inter-temporal decision individuals face is whether or not to repay their loan; in particular, individuals have no access to a savings technology. ${ }^{4}$

Each period comprises three stages; the time line is presented in Figure 1. In the first stage, individuals eligible to borrow choose whether or not to borrow. ${ }^{5}$ Those that choose not to borrow (or are ineligible) pursue an outside option with normalized value $0 .{ }^{6}$ The

\footnotetext{
${ }^{4}$ Bulow and Rogoff (1989) show that when agents have the ability to save, remaining eligible to borrow in the future is not a sufficiently strong incentive to guarantee the repayment of loans. For individuals in developing countries, however, evidence suggests the existence of substantial barriers to savings (see e.g. Dupas and Robinson (2011)). In Mexico, for example, Karlan and Mullainathan (2008) found that of individuals receiving remittances through a particular financial institution, only $38 \%$ had a savings account with that institution, and only half of these individuals saved any portion of their remittances.

${ }^{5}$ The model focuses on the extensive margin of the borrowing decision (i.e. whether to borrow or not) rather than on the intensive margin (i.e. how much to borrow) because in this particular empirical context, the amount each borrower borrows within a group is similar. Online Appendix B.2 extends the model to allow for different borrowers within a group to borrow different amounts.

${ }^{6}$ This assumption implies that there does not exist alternative lenders from which individuals can borrow.
} 
stochastic (and potentially correlated) returns to borrowing are then realized and become known to fellow group members but not the lender. In the second stage, individuals optimally determine the portion of their returns to transfer to their group member to facilitate the repayment of their group member's loan. In the third stage, individuals choose whether or not to repay their loan, given the realized returns and the net transfers received. If an individual is unable or unwilling to repay her loan, she keeps her returns and transfers but becomes ineligible to borrow in future periods. ${ }^{7,8}$ Individuals who repay may continue to borrow in the future, even if their group member fails to repay (in which case they would be assigned a new partner); however, if their group member fails to repay, they will incur a group liability penalty.

Let $i$ refer to one borrower and $g(i)$ refer to her group member and $R_{i}$ and $R_{g(i)}$ indicate the realized value of their respective returns to borrowing. Let $T$ refer to the net transfer made from $i$ to $g(i)$ in a particular period. Let $I$ refer to the cost of repaying the loan (including both principal and the interest rate), which I treat as the numeraire. Let $P$ be the monetary penalty that the bank imposes on an individual if her group member defaults and she continues to borrow. It is assumed that $P \in[0, I]$, where $P=0$ indicates individual liability and $P=I$ indicates full group liability. ${ }^{9}$ Finally, let $V$ indicate the

If there were other lenders, the value of remaining eligible to borrow from a particular lender would fall, which reduces the amount of within group risk sharing that can be sustained without inducing strategic default, thereby increasing default rates. See de Quidt, Fetzer, and Ghatak (2012) for a complete analysis.

${ }^{7}$ The inability of the bank to levy any punishment upon a defaulter other than refusing to lend in the future is consistent with the empirical setting that I examine. In Online Appendix B.1 I show how the model can be extended to incorporate a fixed cost to defaulting, such as a loss of collateral.

${ }^{8}$ For simplicity, in what follows I assume that lenders play a grim trigger strategy; this is in contrast to Tedeschi (2006), who shows that lenders may be able to begin lending to defaulting individuals after a finite number of periods while continuing to incentivize repayment. Alternative punishment strategies will change the value of borrowing $V$; however, conditional on $V$, the impact of group liability on within-group risk sharing and repayment probabilities analyzed below remains unchanged. It is straightforward to show that default rates are minimized when the bank never lends to an individual who has defaulted in the past, as any sort of policy of forgiveness reduces the present discounted value of repaying the loan. It is important to note, however, that minimizing default rates is not equivalent to maximizing borrower welfare (since terminating a borrowing agreement is reduces the welfare of the defaulting borrower).

${ }^{9}$ In Online Appendix B.3, I show how the model can be extended to allow individuals to impose social sanctions on group members. The threat of incurring social sanctions provides an additional incentive for within-group risk sharing. However, because a borrower incurs a social sanction any time she does not make a transfer to her group member when she was able to do so - regardless if she repays or strategically defaults herself - social sanctions do not directly affect the decision of whether or not to strategically default. 
present discounted value of being eligible to borrow, where I omit its dependence on model parameters when possible for the sake of readability.

In what follows, I assume that the present value of the expected returns to borrowing in the next period exceed the cost of repaying the loan in the current period, i.e. $\beta E\left[R_{i}\right]>I$. This ensures that individuals would prefer to repay their loan and remain eligible to borrow rather than default.

\subsection{Equilibrium}

I now solve the model to determine the optimal actions of borrowers conditional on their realized returns to borrowing using backwards induction.

Stage 3: Choosing whether or not to repay In Stage 3, after returns to borrowing have been realized and transfers have been made, if both $i$ and $g(i)$ are able to repay their loans (i.e. $R_{i}-T \geq I$ and $R_{g(i)}+T \geq I$ ), both individuals decide simultaneously whether or not to repay, resulting in the following strategic form game:

\begin{tabular}{|l|l|l|}
\hline$i / g(i)$ & Repay & Default \\
\hline Repay & $R_{i}-T+\beta V-I, R_{g(i)}+T+\beta V-I$ & $R_{i}-T+\beta V-I-P, R_{g(i)}+T$ \\
\hline Default & $R_{i}-T, R_{g(i)}+T+\beta V-I-P$ & $R_{i}-T, R_{g(i)}+T$ \\
\hline
\end{tabular}

Since $\beta V>I$, one Nash equilibrium of this game is for both group members to repay. If $P>\beta V-I$, another possible Nash equilibrium is for both group members to default. Such an equilibrium is undesirable both theoretically (as its payoffs to both players are strictly lower than if they both repaid) and empirically (since the most common outcome we observe in group lending is both members repaying), so I focus on the equilibrium where the loan is repaid if both group members are able to repay.

Suppose instead that one player cannot repay because of insufficient funds. Without loss of generality, assume that $R_{i}-T \geq I$ and $R_{g(i)}+T<I$. Then $g(i)$ will be forced to default. If $i$ repays, she will receive payoff $\beta V-I-P$; if she defaults, she will receive payoff 
zero. Hence, borrower $i$ will repay if the present discounted value of repaying the loan and remaining eligible to borrow in the future exceeds the group liability penalty, i.e. $\beta V-I \geq P$, and strategically default otherwise. ${ }^{10}$

Stage 2: Sending transfers to group members In the second stage, individuals determine how much to transfer to their group member. Suppose that $R_{i} \geq I+\left(I-R_{g(i)}\right)$ and $R_{g(i)}<I$, i.e. borrower $i$ has sufficiently high returns to cover her loan as well her group member's shortfall. Because sending transfers is costly, $i$ will either send a transfer $T_{i}=I-R_{g}(i)$ just sufficient to cover the shortfall or no transfer at all. Borrower $i$ will be willing to make the transfer as long as doing so is less costly than allowing her group member to default, i.e.:

$$
\underbrace{R_{i}-T+\beta V-I}_{\text {make the transfer }} \geq \underbrace{\max \left\{R_{i}+\beta V-I-P, R_{i}\right\}}_{\text {let } g(i) \text { default }}
$$

Hence, the maximum transfer that $i$ will be willing to send, $T^{*}$, is:

$$
T^{*}=\min (P, \beta V-I)
$$

Intuitively, when strategic default is optimal (i.e. when $P>\beta V-I$ ), if $i$ does not cover $g(i), i$ will default too. This makes $i$ ineligible for future loans but saves her from having to repay the current loan, so that the net cost to $i$ for not making the transfer is $\beta V-I$. Hence, it is optimal for $i$ to transfer up to this amount in order to avoid having $g(i)$ default. Similarly, when strategic default is not optimal (i.e. when $P \leq \beta V-I), g(i)$ defaulting will cause $i$ to incur a penalty $P$ and so $i$ will be willing to transfer any amount up to $P$ to avoid this penalty.

Stage 1: Choosing whether or not to borrow In the first stage, eligible individuals choose whether or not borrow prior to their returns being realized. With the outside option

\footnotetext{
${ }^{10}$ When $\beta V-I=P$, a borrower is indifferent between repaying and defaulting; in this case, I assume that the borrower repays.
} 
normalized to 0 , individuals will choose to borrow as long as $V>0$. Let $\pi_{R, R}(P)$ be the probability that the realized returns are such that both $i$ and $g(i)$ repay and let $\pi_{R, D}(P)$ be the probability that the realized returns are such that $g(i)$ defaults and $i$ either strategically defaults or repays while incurring the penalty. The value of borrowing can then be written recursively as:

$$
\begin{aligned}
V(P)= & E\left[R_{i}\right]+\pi_{R, R}(P)(\beta V(P)-I) \\
& +\pi_{R, D}(P) \mathbf{1}\{P \leq \beta V(P)-I\}(\beta V(P)-I-P),
\end{aligned}
$$

Note that transfers do not enter the expression because, from symmetry, expected net transfers are equal to zero. Since the last term of equation (1) is weakly positive, we have:

$$
\beta V(P)-I \geq \frac{\beta E\left[R_{i}\right]-I}{1-\beta \pi_{R, R}(P)}>0,
$$

which establishes the claim above that $\beta E\left[R_{i}\right]>I$ implies $\beta V(P)>I$. Furthermore, since $I>0$ and $\beta>0$, the value of borrowing is strictly positive so all eligible individuals will choose to borrow.

\subsection{Optimal (partial) group liability}

The relationship between borrower repayment behavior and the group liability is summarized in Figure 2. The top left panel depicts the repayment behavior as a function of the realized returns to borrowing when there is no group liability (i.e. $P=0$ ). In this case, group members have no incentive to make transfers to each other, so each borrower will simply repay when her returns are high enough to cover the cost of repayment. Hence, both group members will repay if $R_{i}>I$ and $R_{g(i)}>I$ (Region I), both group members will default if $R_{i}<I$ and $R_{g(i)}<I$ (Region II), and one group will repay while the other defaults if $R_{i}>I$ and $R_{g(i)}<I$ (or $R_{i}<I$ and $R_{g(i)}>I$ ) (Region III). 
Define $P^{*}$ as the group liability penalty that is equal to the present discounted value of continuing to borrow, i.e. $P^{*}$ is the fixed point of the equation $P \equiv \beta V(P)-I$. The properties of $P^{*}$ are explored below in Proposition 1; for now, suppose that it is well defined (i.e. it exists and is unique). The top right panel of Figure 2 depicts how the repayment behavior changes when there is partial group liability $P<P^{*}$. As we saw above, the threat of incurring the group liability penalty provides an incentive for each borrower to transfer an amount up to $P$ in order to cover her group member's shortfall. As a result, both group members will be able to repay if one group member's shortfall is smaller than $P$ and the other group member has sufficiently high returns to repay her own loan and her group member's shortfall. This extends the set of realized returns in which both borrowers are able to repay to include Region IV. The group liability penalty will also extend the set of realized returns in which both borrowers default, since group members may have high enough returns to cover their own loan but insufficiently high returns to cover their own loan and the liability penalty in the case their group member defaults, as depicted in Region V. Hence, imposing group liability increases the probability that both group members repay and increases the probability that both group members default. In contrast, the probability one group member repays while the other defaults declines, as evinced by the shrinking of Region III.

As the group liability penalty increases toward $P^{*}$, Region IV and V expand while Region III contracts. The bottom left panel of Figure 2 shows the relationship between realized returns and repayment behavior when $P=P^{*}$. Since transfers will never exceed $P^{*}$, the area of Regions IV and V are maximized, while the area of Region III is minimized. However, if $P$ exceeds $P^{*}$, borrowers find it optimal to strategically default, which means that Region III becomes a region in which both group members default. This is depicted in the bottom right panel of Figure 2.

The above discussion allows us to characterize the group liability that minimizes default rates. Any $P>P^{*}$ results in (weakly) higher default rates than $P=P^{*}$, since the amount of within-group risk sharing is the same in both cases, but borrowers find it optimal to 
strategically default when $P>P^{*}$. Furthermore, if (loosely speaking) the probability density is higher in the north-east of Figure 2 than in the south-west, then increasing the amount of within-group risk sharing (i.e. expanding Regions IV and V) reduces default rates. In this case, the group liability that minimizes default rates $P=P^{*}$, as this liability maximizes within group risk sharing without incentivizing strategic default.

To formalize this argument, let me make two assumptions concerning the distribution of returns:

Assumption A.1: $\operatorname{Pr}\left\{R_{i}+R_{g(i)} \geq 2 I\right\}+2 \operatorname{Pr}\left\{R_{i} \geq 2 I-R_{g(i)} \cap R_{g(i)} \leq I\right\}<\frac{1}{\beta} \quad$ Assumption A.1 says the event that one borrower will have returns that are sufficiently large to repay both loans while the other does not have enough to pay her own loan is not too much more likely than the event that the total group returns are not sufficient to cover the total cost of both loans. Assumption A.1. is a sufficient condition to ensure that increases in group liability do not increase the probability of repayment so much that the value of borrowing becomes convex in group liability. Loosely speaking, it will hold as long as borrowers' returns are not too negatively correlated, which seems reasonable in contexts where borrowers are subject to similar shocks.

Assumption A.2: For all $P>0, \frac{\partial}{\partial P} \operatorname{Pr}\left\{R_{g(i)} \geq 2 I-R_{i} \cap I-P \leq R_{i} \leq I\right\}>\frac{\partial}{\partial P} \operatorname{Pr}\left\{R_{g(i)}<\right.$ $\left.2 I-R_{i} \cap I \leq R_{i} \leq I+P\right\} \quad$ Assumption A.2 says that the probability a borrower has a high return conditional on her group member having a low return is always higher than the probability a borrower has a low return conditional on her group member having a high return. This is perhaps most easily seen in graphically in Figure 2. Assumption A.2 simply requires that the probability of returns in Region IV occurring is always greater than the probability of Region $\mathrm{V}$ occurring, regardless of $P$. If Assumption A.2 holds, it is straightforward to show that default rates are lower the greater the amount of risk sharing, which allows me to prove the third part of the following Proposition.

Proposition 1. Define $P^{*}$ such that $\beta V\left(P^{*}\right)-I=P^{*}$. Then $P^{*}$ has the following properties: 


\section{1. $P^{*}$ exists and is strictly positive.}

2. If Assumption A.1 holds, $P^{*}$ is unique.

3. If Assumption A.2 holds, $P^{*}$ minimizes default rates.

Proof. See Appendix A.1.

The first two parts of the proposition ensure that $P^{*}$ is a well-defined fixed point. ${ }^{11}$ The fact that $P^{*}$ is strictly positive implies that some form of group liability, however small, will always be preferred to individual liability. The third part of the proposition is the main point of the paper. Intuitively, the fact that a group liability of $P^{*}$ minimizes defaults rates seems like a good thing, as defaulting hurts both the lender (because the loan is not repaid) and the borrower (because the borrower can no longer borrow in the future). ${ }^{12}$ The following corollary formalizes this intuition:

Corollary 1. If Assumption A.2 holds so that $P^{*}$ minimizes default rates, then:

1. For any fixed interest rate, $P^{*}$ maximizes lender revenue.

2. If the lender earns zero profits (e.g. because of a free entry condition or because the lender is benevolent), then $P^{*}$ maximizes borrower welfare.

Proof. See Appendix A.2.

It should be noted that the optimal liability need not be partial; if the value of borrowing is sufficiently large, full liability may be optimal. Figure 3 depicts the optimal group liability rate for a range of model parameters. I normalize the cost of repaying the loan to one and assume that the returns to borrowing (net of the cost of repaying the loan, i.e. principal

\footnotetext{
${ }^{11}$ If assumption A.1 does not hold and $P^{*}$ is not unique, it is straightforward to show the largest fixed point $P^{*}$ minimizes default rates, since will incentivize a larger amount of within-group risk sharing than the smaller fixed points.

${ }^{12}$ If Assumption A.2 does not hold, then it is straightforward to show that increasing group liability will reduce default rates, as the gains from increased amount of risk sharing are dwarfed by the increased probability of being unable to afford to pay the group liability in the event a group member defaults. In this case, optimal group liability is individual liability.
} 
plus interest) of $i$ and $g(i)$ are distributed according to a bi-variate normal distribution with a mean $\mu \equiv \frac{E\left(R_{i}\right)-I}{I} \in[0,1]$, a standard deviation $\sigma \in[0,1]$, a correlation coefficient of 0.5 (top) 0 (middle), or -0.5 (bottom), and an assumed discount value of $\beta=0.9$. All else equal, the optimal group liability increases with the returns to borrowing (which increases the value of borrowing) and decreases with the volatility of returns (which decreases the value of borrowing). For most of the parameter space, the optimal liability is full group liability, as the value of borrowing is sufficiently high so that borrowers will not find it optimal to strategically default.

What are the potential gains from moving to optimal liability? Figures 4 and 5 depict the potential reductions in default rates of moving from individual liability $(P=0)$ and full liability $(P=I)$, respectively, to the optimal liability for a range of model parameters. The reduction in default rates can be substantial; for example, when returns are high and variable, moving from individual liability to optimal liability can reduce default rates by more than $10 \%$; intuitively, this is when borrowers both have an incentive to share risk (since the value of borrowing is high) and risk sharing is especially valuable (since the variance of returns is high). It should also be noted that there exist parameter constellations where there exist gains of moving from both individual liability and full liability toward partial liability. This is similar to the theoretical results found by Rai and Sjöström (2004) and Bhole and Ogden (2010) and suggests that comparing only individual liability and full liability (as, for example, in Gine and Karlan (2011)) may obscure potentially significant gains from moving to partial liability.

There are two main results to take away from Figures 3, 4, and 5: first, the reductions in default from moving to optimal liability are potentially large; second, the optimal liability varies substantially depending on the distribution of returns that borrowers face. Since the returns to borrowing likely vary depending on the empirical context, there is no general proscription of what the optimal group liability should be: in order to achieve the potential gains of moving to the optimal group liability, is first necessary to determine the optimal 
liability in a particular lending environment.

The goal of the remainder of the paper is to develop a general methodology of taking the model to the data and determining the optimal partial liability. To do so, I show how one can recover the model parameters using the observed combinations of repayment and default within borrowing groups. Given some of the strong assumptions underlying the model, before undertaking this quantitative exercise I show that the patterns of repayment in the data are consistent with the qualitative predictions of the model. First, however, I discuss the empirical context on which I focus.

\section{Empirical context}

This section summarizes the lending environment and data that will be used in remainder of the paper.

\subsection{The lending environment}

For the empirics that follow, I use repayment data from Grameen Trust Chiapas (GTC), a large microfinance institution located in Chiapas, Mexico. At the time of study, GTC had 17 branches covering 94 municipalities located throughout the state. GTC offers both individual loans and group loans; individual loans require more collateral (typically $20 \%$ instead of $10 \%$ for the group loans) and usually are for smaller amounts.

During the period of study, the lending process was decentralized. While the central office determined the interest rates, bank branches had almost complete autonomy in determining other policies regarding loans, and substantial leeway was granted to individual loan officers. Typically, after clients chose to pursue a group loan, they formed their own group, were assigned a loan officer, and each client was given their own loan with their own repayment plan. There was no formal process for the assignment of groups to loan officers; typically, interested borrowers who visited a branch office were simply assigned to whichever loan 
officer happened to be available at the time.

If all the loans in the group were successful, each group member was offered a new loan with an increased amount of credit. ${ }^{13}$ If any member of the group was unable to repay their loan at the end of the repayment period, the entire group was supposed to be dissolved and all the loans were supposed to be "restructured" into individual loans with a new payment schedule and continuing interest payments. Once restructured, an individual had to repay their own restructured loan to be able to continue to borrow. However, as emphasized by qualitative interviews with the General Director and several branch managers, there was a substantial amount of variability in the default process. In some cases, if one group member failed to repay, the rest of the group was allowed to continue without that group member without penalty. In other cases, individuals who had been restructured were discouraged from continuing to borrow, even after repaying. There were also cases where borrowers were not allowed to continue to borrow until all group members had repaid their restructured loans in full. The specific penalty to having a group member fail to repay was determined by the loan officer overseeing the loan.

Recall in the previous section that the group liability penalty $P$ was modeled as a monetary cost imposed on a borrower by the lender for having a group member default. The fact that the particular penalty incurred by a borrower for having a group member default varied substantially suggests that the group liability penalty $P$ varied substantially across loan officers. However, the particular way in which the group liability penalty was administered suggests that the group liability penalty penalty $P / I$ can be interpreted as the probability of incurring the full group liability $I$. As long borrowers are risk neutral and transfers are committed to prior to the realization of penalty, the basic intuition of the model presented above (including the decision of how much to transfer) remains the same; however, probabilistic penalties would affect the probability of repayment, as there would be instances in

\footnotetext{
${ }^{13}$ The increasing size of the loan over time is not specifically incorporated into the model, although the discount factor could be interpreted to represent both impatience and the increasing value of the loan (assuming the latter is less than the former).
} 
which the borrower could afford the expected penalty but not the full penalty.

In what follows, I exploit the variation in enforced group liabilities and default rates across loan officers within a lending branch. There are two potential concerns with such an approach. First, because the assignment of loan officers to borrowers was not explicitly random, it could be that there were systematic differences in the borrowers overseen by different loan officers, a point I return to below. ${ }^{14}$ Second, while there did exist substantial variation in the enforced group liability across loan officers, my approach relies on the assumption that each loan officer enforced the same group liability across all of the loans she oversaw; to the extent that individual loan officers varied in the group liability penalty they enforced, the following empirical tests will be biased toward showing no relationship between default rates and the level of group liability.

\subsection{Data}

The administrative data include every group loan made by GTC between 2004 and 2008 . During this period, over 33,000 loans were made to over 18,000 individuals in over 5,000 groups. The data include the start and end dates of the loan, the amount of the loan (principle and interest), some basic information about the client, the borrowing group, and whether the loan was repaid or was in default. In particular, an individual borrower's loan was considered to be in default if the borrower failed to pay off the loan by the due date, in which case the loan was converted from a group loan into a "restructured" individual loan. ${ }^{15}$ (In the data, loans are noted as either "repaid" or "restructured"). Crucially, if one borrower's loan was restructured, her group member's loans were not necessarily restructured, allowing me to observe who in a group loan successfully repaid.

In this paper, I focus on two subsets of the administrative data. The first subset the "structural estimation sample" - comprises all loans made to borrowing groups of two

\footnotetext{
${ }^{14}$ Indeed, qualitative interviews suggested that some particularly entrepreneurial loan officers would visit neighborhoods in attempts to recruit new borrowing groups.

${ }^{15}$ Of the 1,595 borrowers in the data who had their loans restructured, only 37 (2\%) ever took out another loan, suggesting that the assumed "grim trigger" strategy of the bank is a good approximation in this setting.
} 
members. By focusing on the observed repayment and default behavior within these twomember borrowing groups, I can directly apply the model presented in Section 2 to infer the group liability enforced by particular loan officers and structurally estimate the returns to borrowing, which I do in Section 5. The second subset - the "reduced form sample" comprises all other group loans (i.e. loans made to groups with three or more borrowers) who were overseen by the loan officers present in the structural estimation sample. The reduced form sample allows me to see if loan officers who appeared to enforce a group liability near the optimal group liability in the structural estimation sample were able to achieve lower default rates in the other loans not used to infer their enforced group liability, which I do in Section 4

Table 1 presents summary statistics for the two samples. In the structural estimation sample, the average loan was for about about 11,000 pesos (1 US dollar is worth approximately 10 pesos during this period) over a period of 17 weeks; loans in the the reduced form sample were slightly smaller (averaging about 10,000 pesos) over slightly shorter lending periods (averaging 15 weeks). Default rates in both samples were low $-3.6 \%$ in the structural estimation sample and $4.6 \%$ in the reduced form sample - which is similar to default rates in other microfinance lending programs worldwide (Morduch, 1999). While the samples consist of many loans - 7,844 loans in the structural estimation sample and 22,555 loans in the reduced form sample - it should be emphasized that the identifying variation I will be using compares the default rates and enforced group liability across the 62 loan officers. Given the low default rates, a large number of loans per loan officer is necessary to precisely estimate the loan officer specific default probabilities. Table 2 highlights this by presenting the observed repayment combinations in the structural estimation sample of the 7,844 loans, 270 (overseen by 34 different loan officers) were in groups where both borrowers defaulted and only 30 (overseen by 9 different loan officers) were in groups where one borrower defaulted and one repaid. ${ }^{16}$

\footnotetext{
${ }^{16}$ Table 7 in the online appendix presents the frequency of each repayment combination of all loans overseen for each of the 62 loan officers separately in the structural estimation sample.
} 


\section{Testing the model}

Since many important aspects of group borrowing (e.g. adverse selection in group formation, moral hazard hazard in project choice, monitoring costs, etc.) are absent in the model, it remains to be seen how well the model reflects the reality of group borrowing. The purpose of this section is to test the central qualitative prediction of the model: that default rates are minimized at the optimal (partial) liability.

To test this prediction, I rely on two peculiarities of the lending environment mentioned in Section 3.1: first, individual loan officers were given substantial latitude to choose their own level of group liability; and second, within a particular lending branch, the assignment of borrowing groups to loan officers was (in most cases) plausibly random. The two peculiarities suggest a simple test of the model: within a particular branch, is it the case that loan officers who enforced a group liability closer to the optimum liability achieved lower default rates?

The major practical difficulty of implementing such a test is that I do not observe the group liability each loan officer enforced. To overcome this difficulty, I rely on the fact that the group liability enforced by each loan officer can be inferred from the composition of the types of default observed for the loan officer. As is evident in Figure 2, when the group liability enforced increases toward $P^{*}$, the probability of observing one group member repay and the other default, while remaining positive, declines relative to the probability of both group members defaulting, i.e. conditional on some default occurring, it is more likely that both group members default rather than just one group member defaulting. Intuitively, because greater group liability incentivizes greater within group risk sharing, the correlation in the repayment behavior between borrowers increases with the group liability. Once group liability exceeds $P^{*}$, however, strategic default becomes optimal, which implies that it will never be the case that one group member repays while the other defaults: the repayment behavior of the two borrowers is perfectly correlated.

This basic insight suggests the probability a borrower repays conditional on her group

member defaulting is an observable proxy for the group liability enforced. In particular, 
for loan officer $l$, define $\operatorname{frac} R D_{l} \equiv \frac{N_{l}^{R D}}{N^{R D}+N_{l}^{D D}}$ to be the fraction of two-member borrowing groups in which default is observed but one group member repays. From the discussion above, $f r a c R D_{l}$ decreases (but remains positive) as the group liability approaches $P^{*}$ from below and is equal to zero for group liabilities above $P^{*}$. Hence, one test of the model is to see if there exists a non-linear relationship between the default rates a loan officer $l$ achieves and $f r a c R D_{l}$ : while $f r a c R D_{l}$ remains positive, default rates should decline monotonically as $f r a c R D_{l}$ declines, but when $f r a c R D_{l}$ is equal to zero (suggesting the presence of strategic default), default rates should be higher than they are for small positive values of $\operatorname{racR} D_{l}{ }^{17}$

There are several concerns about such a test. First, regressing default rates on a proxy variable constructed from default rates may (mechanically) create a correlation between fracR $D_{l}$ and the error term, thereby biasing the results. This concern motivates using a measure like $f r a c R D_{l}$ which only captures the composition of observed defaults that is invariant to the total level of default. However, to further mitigate concern about mechanical relationships between the level of default and the composition of defaults, I constrain the sample to only include loans overseen by the same loan officer but not used to construct fracR $D_{l}$. Because $f r a c R D_{l}$ is constructed using only loans to two person borrowing groups, I can examine the default rates achieved by the same loan officers for their borrowing groups with three or more borrowers (the "reduced form sample" discussed in Section 3.2).

The second concern is that loan officers that enforce a "better" group liability are also better loan officers in other dimensions, so that the effect of group liability on default rates is confounded by differences in loan officer quality. To address this concern, I control directly for the default rate that a loan officer achieves in her two-person borrowing groups. By controlling for the overall default rate of a loan officer, the identifying variation effectively compares two loan officers who achieved the same overall default rates but for whom the particular composition of default within defaulting borrowing groups differed.

\footnotetext{
${ }^{17}$ Note that the domain of $f r a c R D_{l}$ is not convex, as the model implies that there should never be a fracR $D_{l} \in(0, \psi)$, where $\psi$ is the fraction of group loan defaults where one group repays at the optimal group liability.
} 
The third concern is that the assignment of borrowing groups to loan officers within branch was not explicitly random, so that different loan officers had varying qualities of borrowers. While controlling for the overall default rates mitigates this concern, I can also directly control for borrower and group observables. While it still may be the case that borrowers varied on unobserved dimensions, if controlling for differences among borrowers along observable dimensions does not affect the results, it seems unlikely that differences along unobservable dimensions would be generating the results.

Define $D_{i l b t}$ to be an indicator variable equal to one if individual $i$ overseen by loan officer $l$ in branch $b$ in year $t$ defaults on her loan. Then the above discussion suggests the following estimating equation:

$$
D_{\text {ilbt }}=\gamma_{1} \text { fracR }_{l}+\gamma_{2} \mathbf{1}\left\{\text { fracR }_{l}=0\right\}+\gamma_{3} \operatorname{Pr}\left\{D_{l}\right\}+\mathbf{X}_{i l b t} \beta+\delta_{b}+\delta_{t}+\varepsilon_{i l b t},
$$

where $\operatorname{Pr}\left\{D_{l}\right\}$ is the observed probability of default for loan officer $l$ in two person borrowing groups, $\mathbf{X}_{i l b t}$ is a vector of observable characteristics for individual $i, \delta_{b}$ is a branch fixed effect and $\delta_{t}$ is a year fixed effect. The model predicts that $\gamma_{1}>0$ and $\gamma_{2}>0$ : loan officers whose repay-default combinations are relatively more common than default-default combinations offer lower group liabilities, resulting in less risk sharing and higher default rates; conversely, loan officers where no repay-default combinations are observed offer group liabilities high enough to incentivize strategic default, resulting in higher default rates.

I estimate equation 3 using a linear probability model to allow for the consistent estimation of the fixed effects. Because the variation in $f r a c R D_{l}$ is at the loan officer level, I cluster the standard errors at the loan officer level. Furthermore, I weight each observation by the inverse of the number of two-person borrowing groups observed for each loan officer to correct for the fact that $f r a c R D_{l}$ and $\operatorname{Pr}\left\{D_{l}\right\}$ are sample averages whose variance differs depending on the loan officer. Finally, I include a dummy variable for loan officers who did 
not oversee any defaulting two member borrowing group (and hence for whom $f r a c R D_{l}$ is undefined) and set $f r a c R D_{l}=0$ for those loan officers.

Table 3 presents the results of the regression. The first three columns show the results without controls. Regardless if there are only branch fixed effects, branch and year fixed effects, or branch-year fixed effects, $\gamma_{1}$ and $\gamma_{2}$ are both positive and statistically significant. Columns four through six control for a number of observable borrower characteristics; as is evident, the coefficients on $\gamma_{1}$ and $\gamma_{2}$ are virtually identical and remain statistically significant with the inclusion of the controls, alleviating concerns that the results are being driven by differences across loan officers within branch in the types of borrowers. In all six specifications, the total default rate achieved by a loan officer for two-person borrowing groups is strongly positively correlated with the default rate achieved by a loan officer in groups with more than two people, suggesting that there are persistent differences in the quality of loan officers.

The fact that $\gamma_{1}$ and $\gamma_{2}$ are positive and statistically significant in all specifications indicates that the loan officers for whom the fraction of defaulting group loans where one group member repaid was low (but positive) achieved lower default rates than loan officers for whom repay-default was never observed or repay-default was commonly observed. All specifications find that there is between a six and seven percentage point increase in the probability of default when $f r a c R D_{l}$ is equal to zero compared to when $f r a c R D_{l}$ is positive but arbitrarily small; given the average default rate in the sample is $4.6 \%$, this is a large estimated effect. The effect is even more striking considering that given the low probability of default, it may just be that some of the loan officers for whom $f r a c R D_{l}=0$ may have been offering liabilities that did not incentivize strategic default but simply never had a borrowing group for whom the realized returns caused one group member to default and the other repay. These results provide support for the central prediction of the model: group liability that is high enough to encourage within-group risk sharing but low enough to avoid 
strategic default can substantially reduce default rates. ${ }^{18}$

Given that the model's main prediction appears to be borne out qualitatively in the data, the next section takes the quantitative structure of the model more seriously in order to estimate the optimal partial liability.

\section{Estimating the model}

In this section, I use the observed repayment data for two-person borrowing groups and the structure of the model to estimate the distribution of the returns to borrowing and determine the optimal partial liability. I first present the methodology and then present the results.

\subsection{Methodology}

The goal of the structural estimation is to estimate the optimal partial group liability. To do so, I need to estimate (1) distribution of the returns to borrowing; (2) the discount rate; and (3) the group liability imposed by each loan officer. To estimate these parameters, I rely on repayment data: for every two-person borrowing group, I observe what loan officer oversaw the loan and whether both group members repaid, both group members defaulted, or one group member repaid while the other defaulted.

In order to make the estimation feasible, I normalize the cost of repayment of the loan (principal plus interest) to one and I assume that all borrowers share an identical discount factor $\beta$ and face (ex-ante) identical returns to borrowing that are drawn from a multivariate normal distribution. ${ }^{19}$ As a result, the distribution is fully characterized by the mean and standard deviation of returns, along with the correlation in returns across individuals. In

\footnotetext{
${ }^{18}$ Figure 8 in the online appendix reports the results of a non-parametric version of this regression and also finds that the loan officers with small positive values of $f r a c R D_{l}$ achieve lower default rates than either loan officers with high values or zero values of $f r a c R D_{l}$, suggesting this finding is not a result of the functional form assumption.

${ }^{19}$ Given that assumption that loan officers are randomly assigned to borrowers is more plausible at the branch level, I would ideally estimate the distribution of returns to borrowing for each branch separately. However, because identification arises from the relatively rare events of default, data limitations force me to estimate a common distribution of returns to borrowing for the entire data set.
} 
addition, I assume that each loan officer imposes a common group liability on all of her groups and that the only difference across loan officers is the extent of the group liability enforced. This assumption is crucial for the identification of the model, as it allows me to distinguish strategic default from correlated returns to borrowing. Intuitively, if for some loan officers it is common for one borrower to repay while her group member defaults, I will infer that borrowers returns are not too highly correlated, so for other loan officers for whom such repay-default combinations are never observed, it must be that their borrowers find it optimal to strategically default. In contrast, if the assumption was violated and borrowers differed systematically across loan officers, I may erroneously infer that differences in repayment rates were due to different levels of group liability enforced. Hence, the structural estimation relies on both the variation in the level of group liability enforced by different loan officers and in the "quasi" random assignment of borrowers to loan officers. As I discuss in Section 3.1, it does not seem unreasonable to assume that borrowers are "quasi" randomly assigned to loan officers, and the reduced form results in Section 4 suggest that controlling for borrower observables has little effect on the relationship between group liability and default rates.

The structural estimation uses a maximum likelihood procedure that works as follows. First, I choose a discount rate and a set of parameters that characterizes the distribution of returns to borrowing. Second, given these parameters, I calculate the optimal group liability $P^{*}$ by iterating the value function (1) to find its fixed point, where in each iteration the probabilities of repayment combinations can be calculated given the assumed distribution of returns (see equations (6) and (7) in the Appendix for the regions written as functions of the returns). Third, for all possible levels of group liability, ${ }^{20} \mathrm{I}$ determine the probability of both borrowers repaying, the probability of one borrower repaying and one defaulting, and the probability of both group members defaulting. Fourth, for each loan officer, I find the group liability penalty which maximizes the likelihood of observing the particular default combination of her groups in the data given the assumed parameters. Fifth, I aggregate

\footnotetext{
${ }^{20}$ Since $P \in[0,1]$, I discretize the space in 0.01 steps.
} 
across loan officers to determine the total likelihood and iterate the entire process to find the distribution of returns that maximizes this likelihood.

Mathematically, for each loan officer $l \in\{1, \ldots, L\}$ I observe $N_{l}^{R R}$ groups where both borrowers repaid, $N_{l}^{R D}$ groups where one borrower repaid and one defaulted, and $N_{l}^{D D}$ groups where both group members defaulted. Define $\theta \equiv\{\mu, \sigma, \rho, \beta\}$ to be the set of parameters to estimate, where $\mu$ is the mean returns to borrowing (net of the cost of repaying the loan), $\sigma$ is the standard deviation of returns, $\rho$ is the correlation in returns, and $\beta$ is the discount rate. Let $\pi_{j}(\theta, P), j \in\{R R, R D, D D\}$ be the probability of observing repayment combination $j$ as a function of the parameters $\theta$ and group liability $P$. Then the estimated parameters $\hat{\theta}$ are the ones which maximize the log likelihood of observing the actual repayment combinations observed in the data:

$$
\hat{\theta} \equiv \arg \max _{\theta \in \Theta} \sum_{l=1}^{L} \max _{P_{l} \in[0,1]} \sum_{j \in\{R R, R D, D D\}} N_{l}^{j} \ln \pi_{j}\left(\theta, P_{l}\right)
$$

As is common with maximum likelihood estimation, numerical methods are required to estimate equation 4. It is important to note that the the MLE procedure does not only estimate the vector of structural parameters $\theta$, it also estimates a vector of group liabilities $P$, one for each loan officer. Because the likelihood function is not smooth in $P$, for all $\theta$, I first conduct an inner-loop grid-search over all $P \in[0,1]$ (in 0.01 intervals) and then maximize the likelihood over $P$ for each loan officer separately. ${ }^{21}$ To find $\hat{\theta}$, I then conduct an exhaustive outer-loop grid search of all combinations of values of $\mu \in[0,1], \sigma \in(0,1]$, $\rho \in[-0.5,0.5]$ and $\beta \in[0.8,0.95]$ satisfy the model restriction $\beta \mu>1$. Because of the inner nest of maximization across the vector of group liabilities $P$, I use a bootstrap procedure to calculate the standard errors and report (percentile) confidence intervals. ${ }^{22}$

\footnotetext{
${ }^{21}$ Because the probability of $\{$ Repay,Default $\}$ is zero if the loan officer's group liability exceeds the optimal liability, the log likelihood is ill-defined, so I find the group liability that maximizes the likelihood of each loan officer.

${ }^{22}$ In particular, I re-do the structural estimation for 600 bootstrap samples. Given the time intensive nature of the bootstrap procedure, I use a numerical gradient-based optimization procedure rather than a grid search for the outer loop for each bootstrap procedure, which reduces the estimation time to a
} 
Figure 2 provides intuition for how the group liability of each loan officer can be estimated from the repayment data, i.e. the "inner loop" of equation 4. Loan officers for whom no group had ever defaulted will be estimated to have been enforcing the optimal group liability, as the default rates are minimized at $P^{*}$. Loan officers who oversaw defaulting groups but for whom no group had one member repay and one member default will be estimated to have full group liability, since the lack of repay-default groups is rationalized by the borrower's preferring to strategically default. Finally, loan officers who oversaw some groups where one member repaid and the other defaulted will be estimated to have enforced a group liability no greater than the optimal, as it must not have been optimal for borrowers to strategically default.

Figure 2 also illustrates how each of the model parameters comprising $\theta$ can be separately identified conditional on the estimated loan officer group liabilities $\hat{P}_{l}$, i.e. the "outer loop" of equation 4 . All else equal, increasing the mean returns to borrowing $\mu$ increases the probability density in the north-east of the realized returns space, increasing the predicted probability of observing both group members repaying for any group liability enforced. Increasing the standard deviation in returns to borrowing $\sigma$ causes the probability density to become more uniform across the realized returns space, increasing both the probability that both group members default and the probability that one group member repays and the other defaults. Increasing the correlation of returns to borrowing $\rho$ increases the probability density along the 45 degree line in the realized returns space, increasing the predicted probability of both group members defaulting and both group members repaying, but decreasing the probability that one group member repays while the other defaults. Finally, increasing the discount factor $\beta$ increases the present discounted value of borrowing, thereby increasing the optimal group liability and the maximum amount of risk sharing that can be sustained, allowing for there to be greater variation across loan officers in how probable one group member defaults while the other repays.

manageable 600 processor-hours. Figure 6 shows that the likelihood function (given the inner loop grid search over $P$ ) is smooth, justifying the use of a gradient-based optimization procedure. 


\section{$5.2 \quad$ Results}

The structural estimates are presented in the first section of Table 4 . The average return to borrowing (over and above the principal and interest) is estimated to be 0.23 (with a standard error of 0.092) Since each loan is approximately 4 months long and the annual interest rate is about $46 \%$, this suggests that gross annual returns to borrowing are 100.0 percent $(3 \times \ln (1.23)+\ln (1.46))$ (with a standard error of 0.196 percent). The standard deviation of returns to borrowing is estimated to be 0.24 (with a standard error of 0.059), which implies that borrower will get negative returns (net of principal plus interest) on a loan 17 percent of the time. The correlation of returns across borrowers is estimated to be -0.44 (with a standard error of 0.106 ). This negative estimated correlation in returns is somewhat surprising, but it should be noted that group members who are optimally choosing their group members would prefer to find someone whose returns are negatively correlated, since the negative correlation increases the probability both group members repay if they are risksharing. (Note too that the bootstrap simulations imply a 5\%/95\% confidence interval of $[-0.44,-0.165]$, which suggests that the point estimate of the maximum likelihood procedure is on the low end). ${ }^{23}$ Finally, the discount factor is estimated to be 0.91 (with a standard error of 0.083$) \cdot{ }^{24}$

To get a sense of how well identified each of the model parameters is, Figure 6 shows how the log likelihood changes with each parameter holding constant the other three (but allowing the group liabilities $P$ to be re-estimated in the inner-loop as $\theta$ changes). As is evident, small changes to either the average returns or the standard deviation of returns substantially affects the log-likelihood, whereas the affect of changing the correlation of returns on the log likelihood is smaller and the log likelihood varies very little with changes

\footnotetext{
${ }^{23}$ Indeed, an earlier version of the paper estimates a positive correlation in returns to borrowing across group members. However, this estimation was for a different sample of borrowers, making a direct comparison difficult.

${ }^{24}$ While Assumption 1 does not hold for $\hat{\theta}$, it is straightforward to verify that a weaker sufficient condition for uniqueness, namely that $\frac{\partial}{\partial P}\left(1-\beta \pi_{R, R}(P)\right)>0$ for all $P \in[0,1]$ (see Appendix A.1) does hold; hence the optimal group liability is unique given the estimated returns to borrowing.
} 
to the discount factor around the optimum.

To get some sense of how the estimated loan officer specific group liabilities are identified, Figure 7 compares the estimated loan officer liability to the $f r a c R D_{l}$ used in the Section 4 as a proxy for group liability. Consistent with the discussion above, the twenty-six loan officers (overseeing 3,548 loans) who were estimated to have enforced full liability are those loan officers for whom there were no observed instances in which one group member repaid and the other defaulted but there were instances in which both group members defaulted; these loan officers are indicated by the large circle in the bottom right corner. The other large circle in that corner represents the twenty-seven loan officers (overseeing 1,964 loans) for whom no default of any kind was ever observed: the structural estimation assigns these loan officers the optimal group liability. For the remaining nine loan officers (overseeing 2,332 loans), those with a greater fraction of loans where one group member defaulted and one repaid relative to both group members defaulting tend to be estimated to be assigned lower enforced liabilities, consistent with them incentivizing less within-group risk sharing (the correlation between the estimated group liability and $\operatorname{fracR} D_{l}$ for these loan officers is -0.78). Hence, the structural estimation implies that the proxy used in Section 4 does a good job capturing the variation across loan officers in the enforced group liability.

The second section of Table 4 shows how well the model is able to capture the observed prevalence of default given the estimated parameters. The model perfectly predicts the overall default rate $(3.63 \%)$, slightly over predicts the probability of both group members defaulting (3.45\% versus $3.44 \%$ in the data) and slightly under-predicts the probability of one group member defaulting and one repaying ( $0.35 \%$ versus $0.38 \%$ in the data). These slight differences in probability amount to the model incorrectly predicting the repayment of roughly three of the 7,844 loans in the sample.

Given the estimated returns to borrowing and discount rate, the model implies that the optimal group liability is 0.98 , i.e. lenders should enforce nearly full liability. The bootstrapped confidence interval shows that we can reject (at the one-sided $10 \%$ level) the 
optimal group liability is full liability and we can reject (at the one-sided $5 \%$ level) that the optimal group liability is individual liability. How large are the gains of moving to the optimal (partial) liability? Given the estimated negative correlation in borrowing and the large optimal group liability (which implies substantial within-group risk sharing), the probability of having realized returns that induce strategic default is negligible (less than $0.001 \%$ ), indicating that full liability would achieve default rates nearly as low as the optimal liability. As a result, the predicted reduction in default of moving all loan officers to the optimal group liability is modest and is driven almost entirely by changing the liability of those loan officers estimated to have been enforcing less than optimal group liability. All told, the model predicts that the overall default rate would fall from $3.61 \%$ to $3.51 \%$. To put this in context, if all loan officers in the sample enforced the optimal group liability, the model predicts there would be about ten fewer defaults in the sample of 7,844 loans.

Why are these predicted reductions in default so much smaller than those estimated using out of sample loans in Section 4? One possibility is that moving to an optimal group liability results in a greater reduction in default rates when there are more than two group members. In Online Appendix B.4, I extend the model to incorporate multiple group members and show that the incentive to strategically default increases as the number of group members forced to default increases, as the larger group liability penalty is shared amongst fewer repaying group members. However, this effect needs to be contrasted with the greater potential for risk-sharing within larger groups, making the effect of group size on default theoretically ambiguous.

\section{Conclusion}

This paper developed a simple model of group lending that contrasts the costs and benefits of group liability. The model implied that greater group liability encourages greater within group risk sharing, but a group liability that is too large may induce borrowers to strategi- 
cally default. While simple, the model incorporated several realistic characteristics of group lending, including correlated returns to borrowing, limited liability, and forward-looking behavior.

The paper then provided evidence that loan officers who enforced a high - but not too high - group liability achieved lower default rates using repayment data from a large microfinance institution in southern Mexico. Specifically, loan officers for whom one borrower repaid when their group member defaulted in two person borrowing groups achieved substantially lower default rates in other loans than loan officers for whom this never occurred or form whom it occurred more frequently. Consistent with this result, structural estimation of the model suggests that a partial group liability less than full group liability could lead to a reduction in default rates.

Hence, this paper suggests a easily implementable policy proscription that has the potential to reduce default rates in group lending programs. However, it should be emphasized that these empirical findings rely on the experience of one particular lender. Since the optimal liability varies substantially depending on the model fundamentals, it is important that the group liability is tailored to each empirical setting. One advantage of the estimation strategy developed in this paper is its modest data requirements, which hopefully can facilitate its replication in other contexts. 


\section{References}

Abbink, K., B. Irlenbusch, and E. Renner (2006): "Group size and social ties in microfinance institutions," Economic Inquiry, 44(4), 614-628.

Ahlin, C., And R. Townsend (2007): "Using repayment data to yest across models of joint liability lending," The Economic Journal, 117(517), F11-F51.

Armendariz, B., And J. Morduch (2010): The Economics of Microfinance. The MIT Press.

Armendariz de Aghion, B. (1999): "On the design of a credit agreement with peer monitoring," Journal of Development Economics, 60(1), 79-104.

Baland, J.-M., R. Somanathan, and Z. Wahhaj (2013): "Repayment incentives and the distribution of gains from group lending," Journal of Development Economics, 105, $131-139$.

BanerJee, A., T. Besley, and T. Guinnane (1994): "Thy neighbor's keeper: The design of a credit cooperative with theory and a test," The Quarterly Journal of Economics, $109(2), 491-515$.

Besley, T., And S. CoAte (1995): "Group lending, repayment incentives and social collateral," Journal of Development Economics, 46(1), 1-18.

Bhole, B., And S. OGden (2010): "Group lending and individual lending with strategic default," Journal of Development Economics, 91(2), 348-363.

Bulow, J., And K. Rogoff (1989): "Sovereign debt: Is to forgive to forget?," The American Economic Review, pp. 43-50.

Chowdhury, P. (2005): "Group-lending: Sequential financing, lender monitoring and joint liability," Journal of Development Economics, 77(2), 415-439.

Conning, J. (1999): "Outreach, sustainability and leverage in monitored and peermonitored lending," Journal of Development Economics, 60(1), 51-77.

De Quidt, J., T. Fetzer, And M. Ghatak (2012): "Market structure and borrower welfare in microfinance," Working paper.

(2013): "Group Lending Without Joint Liability," CEPR Discussion Papers 9578.

Dowla, A., And D. BARUA (2006): The poor always pay back: The Grameen II story. Kumarian Press, Inc.

Dupas, P., And J. Robinson (2011): "Why Don't the Poor Save More? Evidence from Health Savings Experiments," Working paper.

Feigenberg, B., E. Field, And R. Pande (2011): "The economic returns to social interaction," Working paper. 
FischeR, G. (2012): "Contract structure, risk sharing and investment choice," Working paper.

Fischer, G., And M. Ghatak (2010): "Repayment frequency in microfinance contracts with present-biased borrowers," Economic Organisation and Public Policy Discussion Papers Series, 21.

Gangopadhyay, S., M. Ghatak, and R. Lensink (2005): "Joint liability lending and the peer selection effect," The Economic Journal, 115(506), 1005-1015.

Ghatak, M. (1999): "Group lending, local information and peer selection," Journal of Development Economics, 60(1), 27-50.

(2001): "Screening by the company you keep: Joint liability lending and the peer selection effect," The Economic Journal, 110(465), 601-631.

Ghatak, M., and T. Guinnane (1999): "The economics of lending with joint liability: theory and practice," Journal of Development Economics, 60(1), 195-228.

Gine, X., and D. Karlan (2011): "Group versus individual liability: short and long term evidence from Philippine microcredit lending groups," Working paper.

Giné, X., K. Krishnaswamy, and A. Ponce (2011): "Strategic default in joint liability groups: Evidence from a natural experiment in India," Working paper.

Karlan, D., and S. Mullainathan (2008): "Commitment savings accounts for remittance receivers in Mexico," http://www.poverty-action.org/project/0013.

Madajewicz, M. (2003): "Does the credit contract matter? The impact of lending programs on poverty in Bangladesh," Working paper.

(2004): "Joint liability versus individual liability in credit contracts," Working paper.

Morduch, J. (1999): "The Microfinance Promise," Journal of Economic Literature, 37(4), 1569-1614.

RaI, A., And T. SJÖström (2004): "Is Grameen lending efficient? Repayment incentives and insurance in village economies," Review of Economic Studies, 71(1), 217-234.

Stiglitz, J. (1990): "Peer monitoring and credit markets," The World Bank Economic Review, 4(3), 351-366.

Tedeschi, G. A. (2006): "Here today, gone tomorrow: Can dynamic incentives make microfinance more flexible?," Journal of Development Economics, 80(1), 84-105.

Yunus, M. (2002): "Grameen Bank II: Designed to open new possibilities," Grameen Dialogue. 


\section{Figures and tables}

Figure 1: Model time line

\begin{tabular}{|c|c|c|c|c|}
\hline & $\begin{array}{c}\text { Borrowing returns realized } \\
\text { (unobserved to bank, } \\
\text { observed to group } \\
\text { members) }\end{array}$ & \multicolumn{2}{|c|}{$\begin{array}{l}\text { Individuals with } \\
\text { insufficient returns } \\
\text { net of transfers } \\
\text { default }\end{array}$} & $\begin{array}{l}\text { Defaulting individuals become } \\
\text { ineligible to borrow and their } \\
\text { repaying group members incur } \\
\text { a group liability penalty }\end{array}$ \\
\hline 1 & & & & \\
\hline $\begin{array}{c}\text { Stage } 1 \\
\text { Eligible individuals } \\
\text { decide whether or } \\
\text { not to borrow }\end{array}$ & $\begin{array}{r}\text { Stc } \\
\text { Group } \\
\text { may ser } \\
\text { trar }\end{array}$ & $\begin{array}{l}\text { bers } \\
\text { ceive }\end{array}$ & $\begin{array}{r}G \\
\text { simu } \\
\text { whet }\end{array}$ & $\begin{array}{l}\text { ge } 3 \\
\text { nembers } \\
\text { usly decide } \\
\text { not to repay }\end{array}$ \\
\hline
\end{tabular}


Figure 2: Group liability and the probability of default
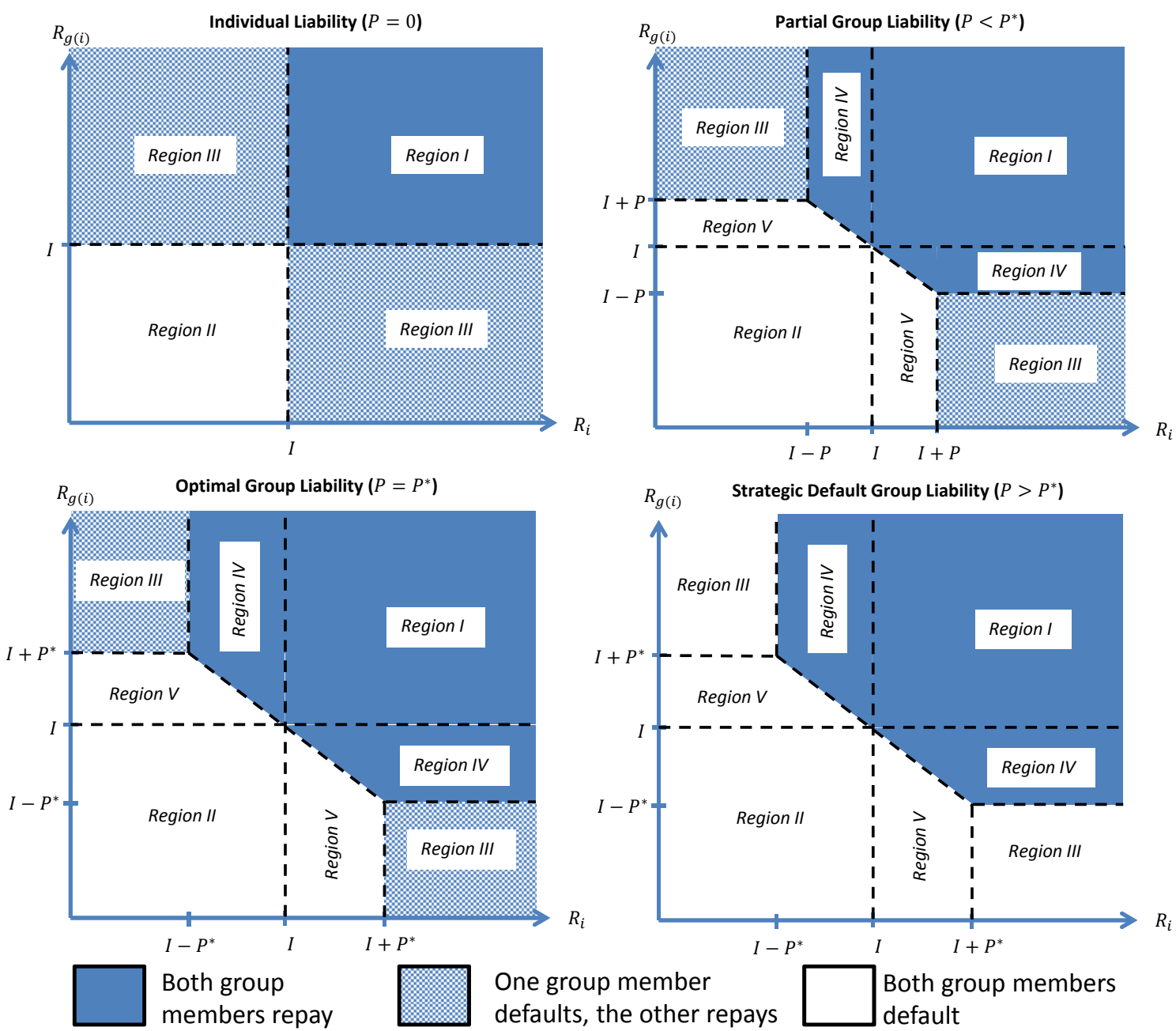

Notes: This figure shows the mapping between realized returns to borrowing and the repayment decisions of individuals as a function of the group liability imposed. Increasing the group liability from individual liability increases the range in which both group members repay by incentivizing within-group transfers. When group liability becomes too large, however, it induces strategic default. 
Figure 3: Optimal partial liability as a function of returns to borrowing

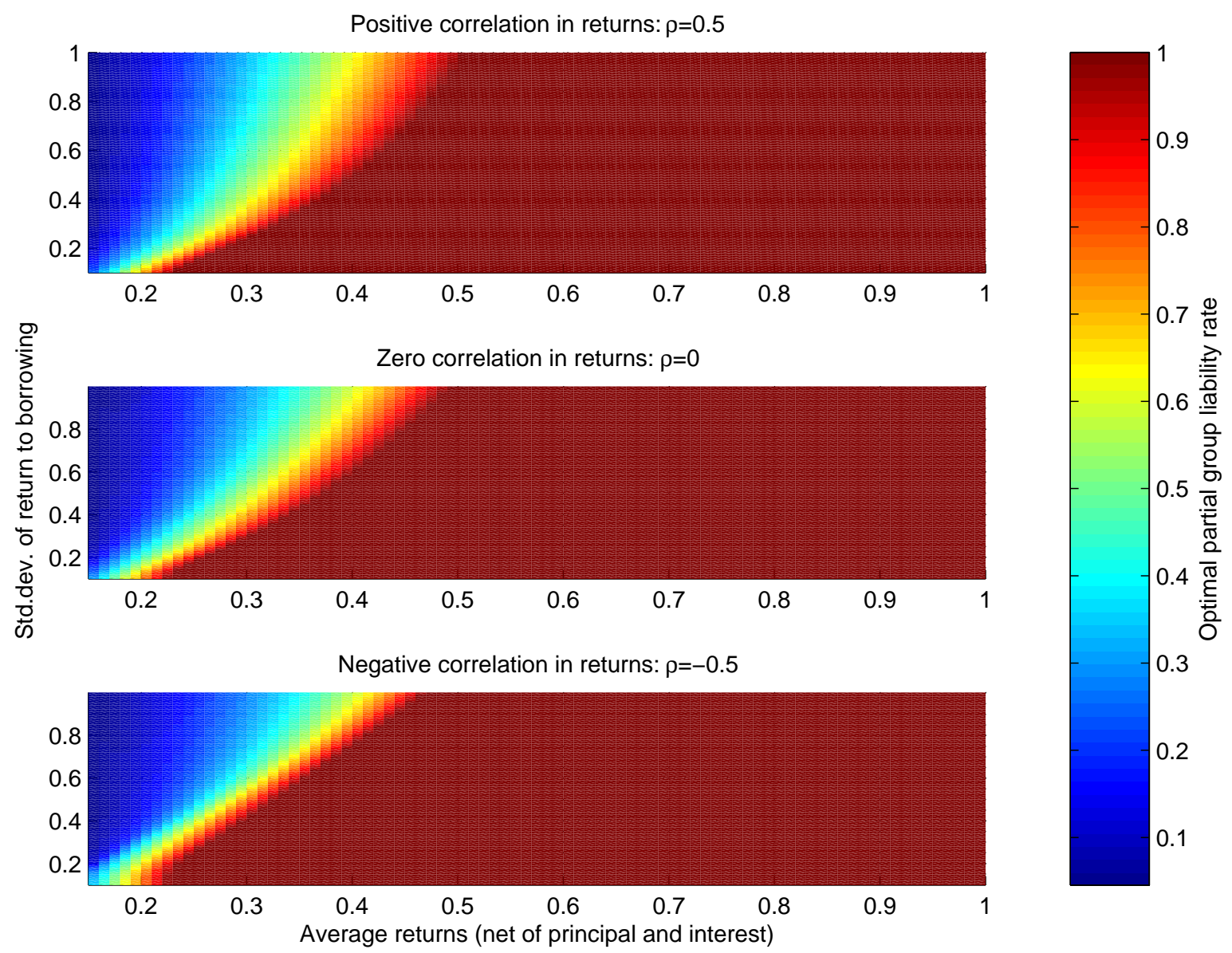

Notes: This figure shows the optimal partial group liability rate as a function of the mean and standard deviation of the returns to borrowing. Returns to borrowing (net of the cost of repaying the loan, which is normalized to one) are assumed to be bivariate normally distributed with a correlation between group members of 0.5 (top panel), 0 (center panel), or -0.5 (bottom panel). 
Figure 4: Reduction in default rates moving from individual liability to optimal group liability
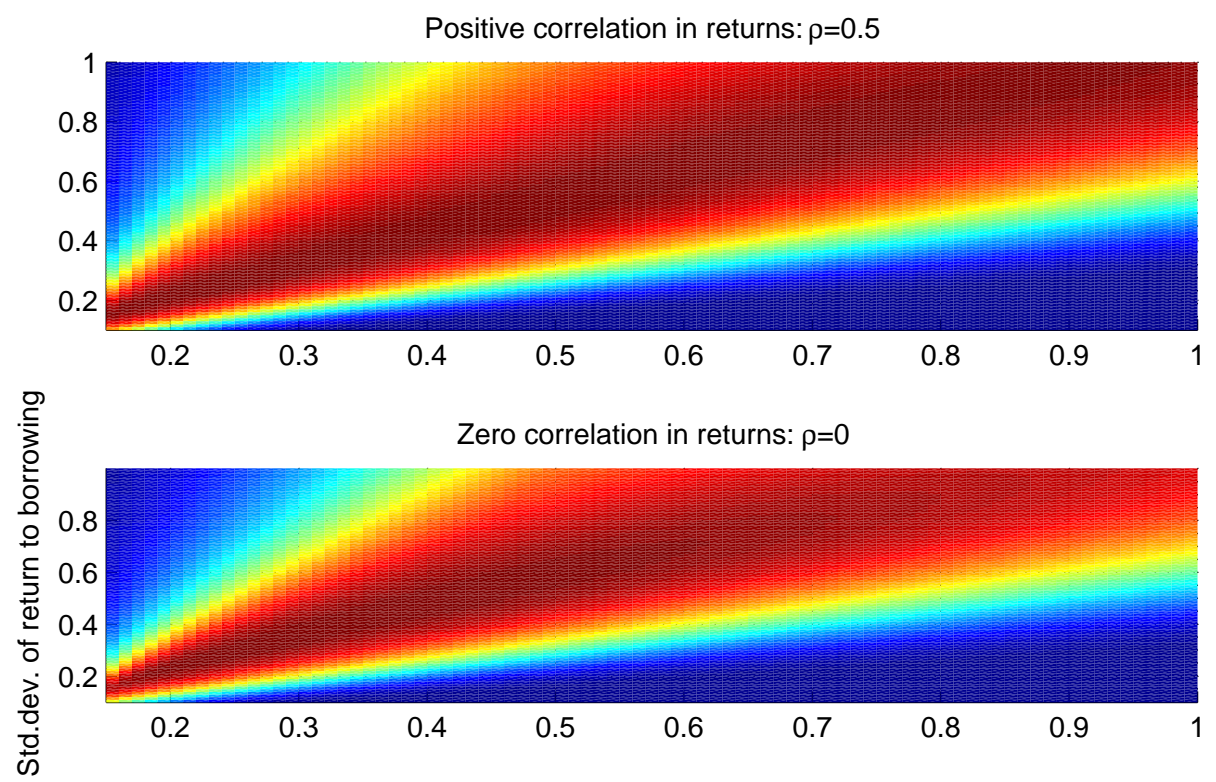

Negative correlation in returns: $\rho=-0.5$
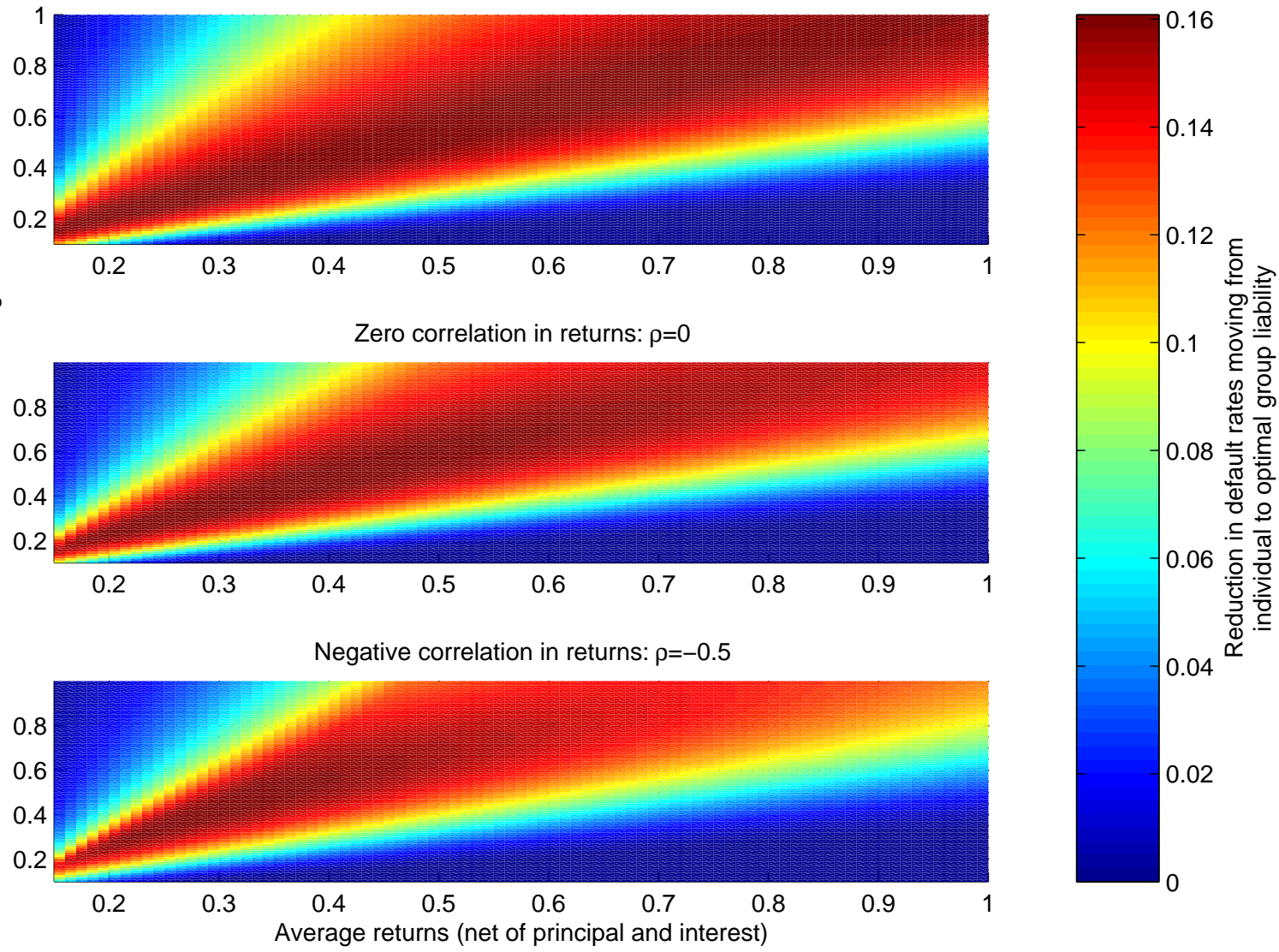

Notes: This figure shows the reduction in default rates from moving from individual liability (i.e. $P=0$ ) to optimal group liability (i.e. $P=T^{*}$ ) as a function of the mean and standard deviation of the returns to borrowing. Returns to borrowing (net of the cost of repaying the loan, which is normalized to one) are assumed to be bivariate normally distributed with a correlation between group members of 0.5 (top panel), 0 (center panel), or -0.5 (bottom panel). 
Figure 5: Reduction in default rates moving from full liability to optimal group liability
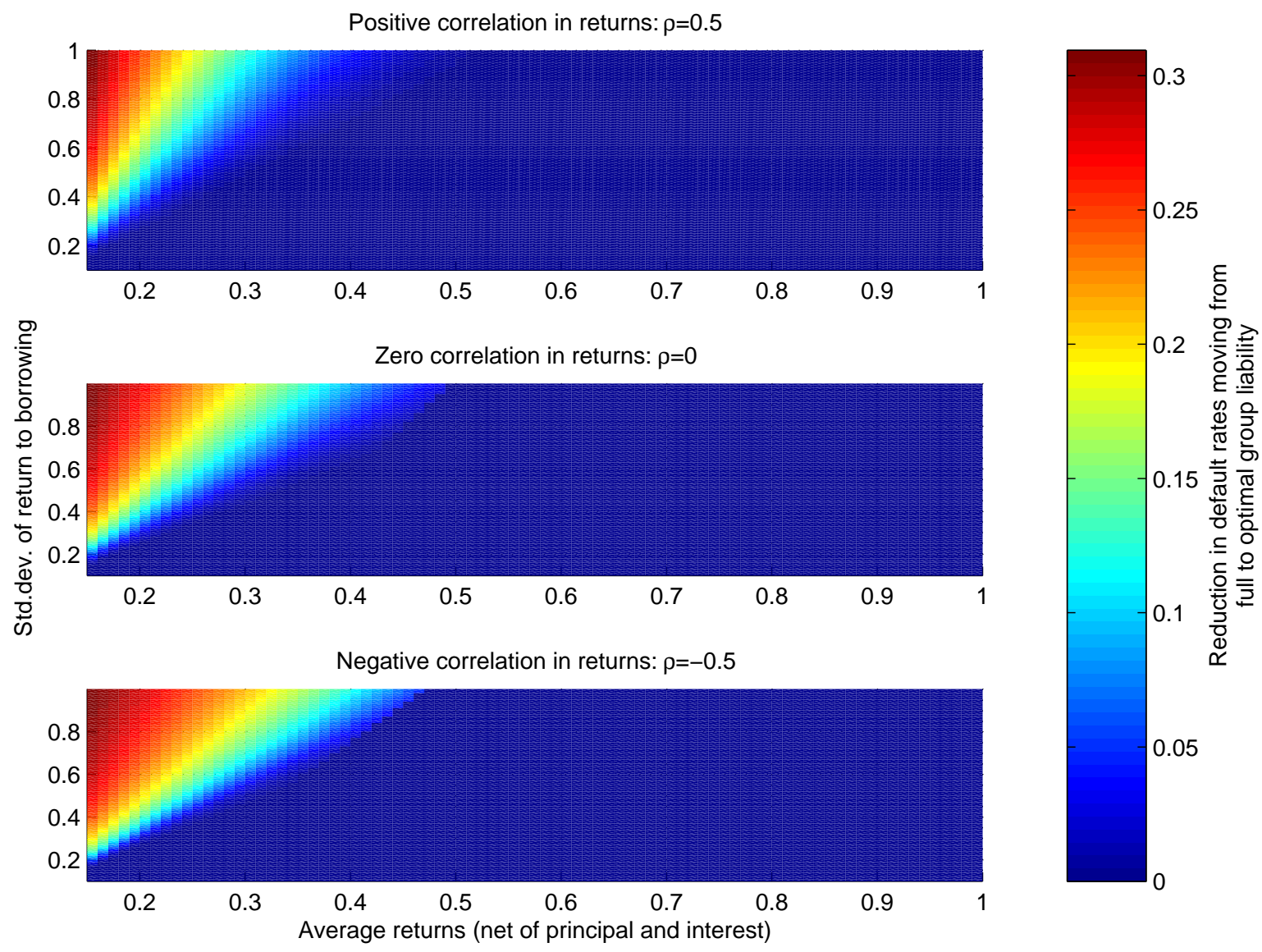

Notes: This figure shows the reduction default rates from moving from full group liability (i.e. $P=1$ ) to optimal group liability (i.e. $P=T^{*}$ ) as a function of the mean and standard deviation of the returns to borrowing. Returns to borrowing (net of the cost of repaying the loan, which is normalized to one) are assumed to be bivariate normally distributed with a correlation between group members of 0.5 (top panel), 0 (center panel), or -0.5 (bottom panel). 
Figure 6: Structural estimation of the returns to borrowing: marginal log likelihood function

Marginal log-likelihood function for $\mu$ : $\sigma=0.24, \rho=-0.44, \beta=0.91$

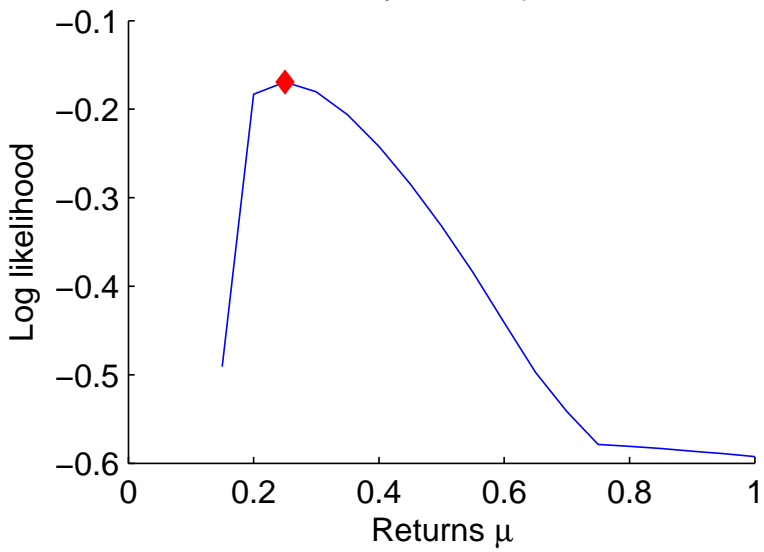

Marginal log-likelihood function for $\rho$ : $\mu=0.23, \sigma=0.24, \beta=0.91$

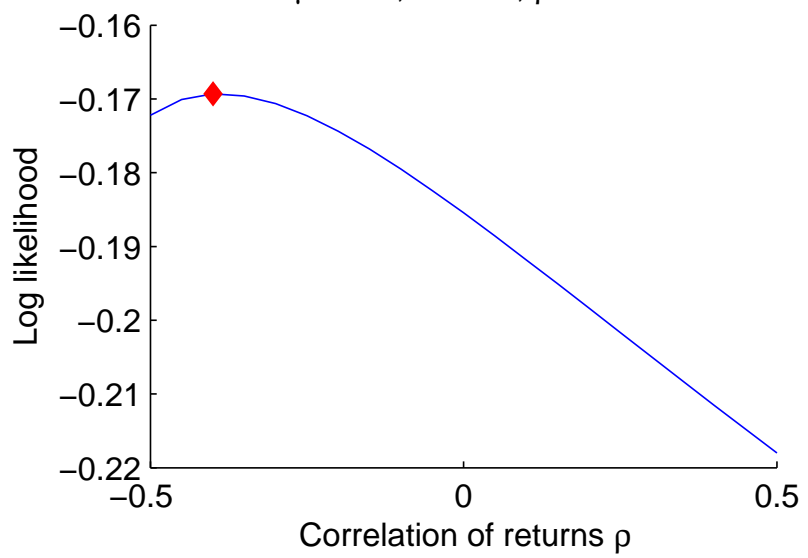

Marginal log-likelihood function for $\sigma$ : $\mu=0.23, \rho=-0.44, \beta=0.91$

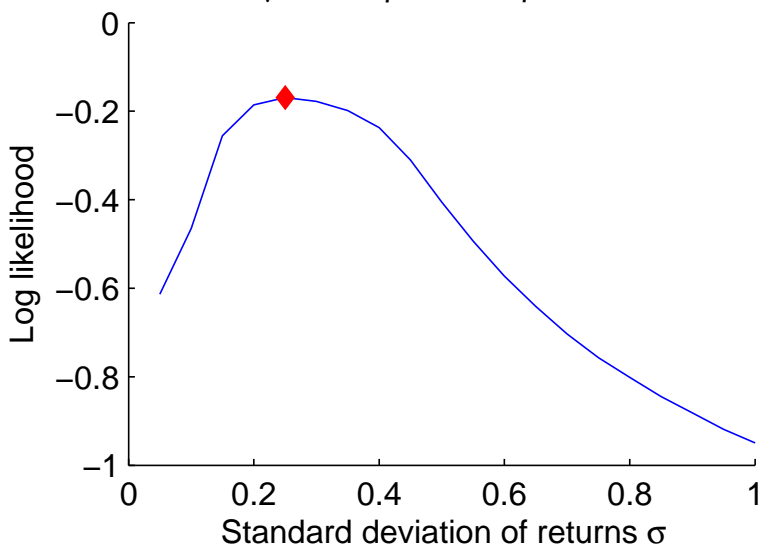

Marginal log-likelihood function for $\beta$ : $\mu=0.23, \sigma=0.24, \rho=-0.44$

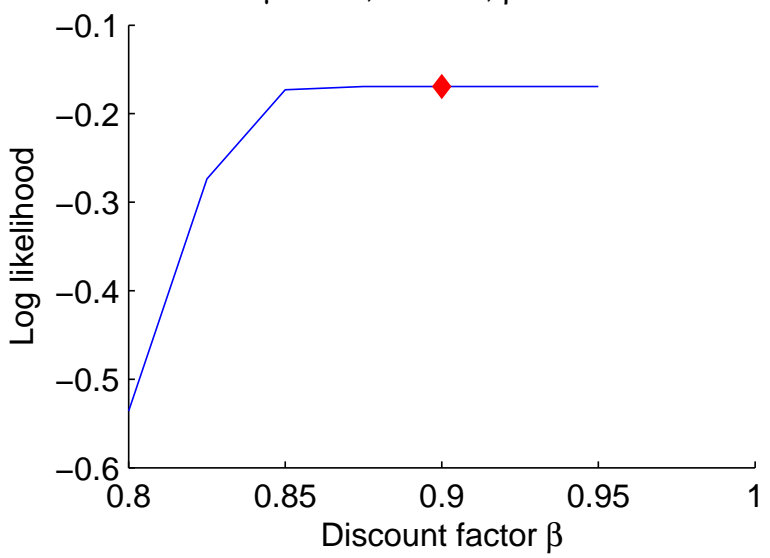

Notes: This figure shows how the log-likelihood function changes with each parameter governing the returns to borrowing, holding other parameters constant at their optimal values, but allowing the estimated loan-officer specific group liabilities to change optimally. The structural estimates are determined using a grid search over all possible parameter constellations. Because the loan-officer specific group liabilities are determined in an inner-maximization loop, the standard errors are calculated using a bootstrap procedure. 
Figure 7: The estimated loan officer penalties and observed ratio of Repay-Default to DefaultDefault

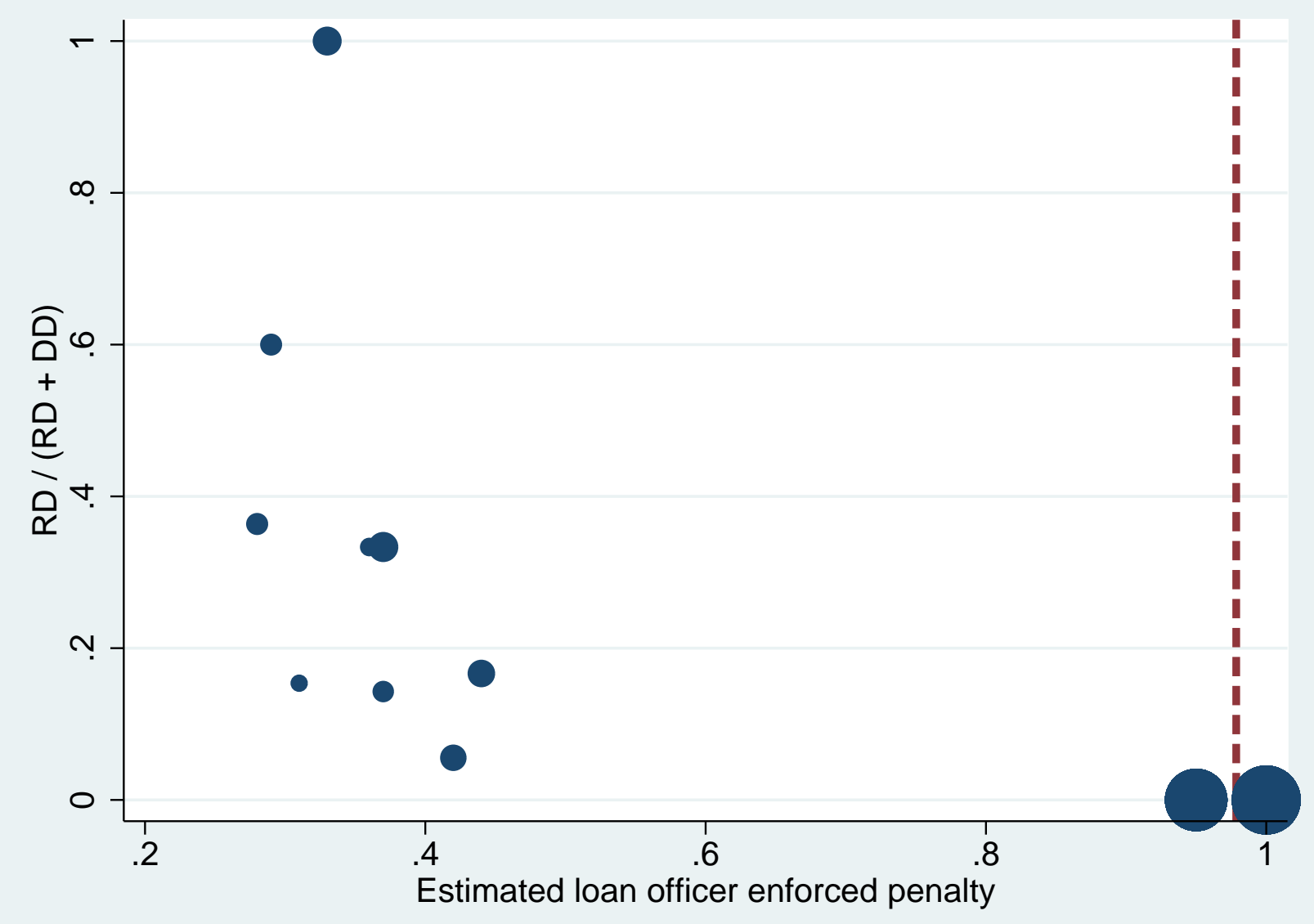

Notes: This figure shows the relationship between the estimated loan officer specific group liability penalty $\hat{P}_{l}$ and the observed ratio of the number of groups for the loan officer that were observed to Repay-Default relative to the number of groups that were observed to default. The size of the circles are proportional to the total number of loans overseen. The dashed red-line indicates the threshold group liability penalty above which strategic default becomes optimal. Consistent with the theory, loan officers for whom Repay-Default combinations were relatively more common in two person borrowing groups than DefaultDefault combinations are estimated to have enforced lower group liabilities. The large circle immediately to the left of the strategic default line corresponds to all loan officers for whom no two-person borrowing group ever defaulted; the large circle to the right of the strategic default line corresponds to all loan officers for whom in at least one two-person borrowing group Default-Default was observed but no Repay-Default combination was observed. 
Table 1: Summary Statistics

\section{Structural Estimation Sample}

\begin{tabular}{lllll}
\hline Variable & Mean & Std. Dev. & Min & Max \\
\hline Loan Default & 0.036 & 0.187 & 0 & 1 \\
Length of loan (weeks) & 17.245 & 8.025 & 1 & 52 \\
Interest Rate (annualized) & 0.460 & 0.058 & 0.000 & 1.725 \\
Number of group members & 2 & 0 & 2 & 2 \\
Loan amount (000s pesos) & 11.088 & 12.681 & 0.531 & 150 \\
Borrower Age & 38.752 & 11.432 & 5.769 & 105.780 \\
Borrower Sex (1=male) & 0.284 & 0.451 & 0 & 1 \\
Borrower Tenure with bank (days) & 425.365 & 264.493 & 42 & 1483 \\
Observations & \multicolumn{4}{c}{7844} \\
r
\end{tabular}

\section{Reduced Form Sample}

\begin{tabular}{lllll}
\hline Variable & Mean & Std. Dev. & Min & Max \\
\hline Loan Default & 0.046 & 0.208 & 0 & 1 \\
Length of loan (weeks) & 14.827 & 7.397 & 2 & 56 \\
Interest Rate (annualized) & 0.460 & 0.048 & 0.000 & 0.842 \\
Number of group members & 5.394 & 3.760 & 3 & 31 \\
Loan amount (000s pesos) & 10.113 & 12.506 & 0.385 & 260 \\
Borrower Age & 38.707 & 11.681 & 4.424 & 106.157 \\
Borrower Sex (1=male) & 0.147 & 0.355 & 0 & 1 \\
Borrower Tenure with bank (days) & 341.300 & 221.679 & 31 & 2178 \\
Observations & \multicolumn{2}{c}{22555}
\end{tabular}

Notes: This table shows the summary statistics for the two samples used in the paper. The structural estimation sample includes all two member borrowing groups. The reduced form sample includes all borrowing groups with three or more members whose loan officer oversaw a loan in the structural estimation sample. 
Table 2: Default Combinations in Structural Estimation Sample

\begin{tabular}{lllll} 
& Repay-Repay & Repay-Default & Default-Default & Total \\
\hline Number of loans & 7,544 & 30 & 270 & 7,844 \\
Number of loan officers & 62 & 9 & 34 & 62 \\
\hline
\end{tabular}

Notes: This table shows the frequency of all repayment combinations amongst all two-person borrowing groups in the structural estimation sample, as well as the number of loan officers who oversaw at least one borrowing group of a particular repayment combination. 
Table 3: Evidence of Optimal Partial Liability

\begin{tabular}{|c|c|c|c|c|c|c|}
\hline & (1) & $(2)$ & $(3)$ & (4) & $(5)$ & (6) \\
\hline $\mathrm{RD} /(\mathrm{RD}+\mathrm{DD})$ in two & $0.080^{*}$ & $0.080^{*}$ & $0.085^{*}$ & $0.082^{* *}$ & $0.080 * *$ & $0.089^{* *}$ \\
\hline person borrowing groups & $(0.042)$ & $(0.042)$ & $(0.046)$ & $(0.040)$ & $(0.039)$ & $(0.042)$ \\
\hline No RD two person & $0.065 * *$ & $0.064^{* *}$ & $0.069^{* *}$ & $0.065 * *$ & $0.063^{* *}$ & $0.071^{* * *}$ \\
\hline borrowing groups & $(0.026)$ & $(0.027)$ & $(0.027)$ & $(0.026)$ & $(0.026)$ & $(0.026)$ \\
\hline Probability of default in & $1.667^{* * *}$ & $1.695^{* * *}$ & $1.658 * * *$ & $1.602^{* * *}$ & $1.622^{* * *}$ & $1.607^{* * *}$ \\
\hline $\begin{array}{l}\text { two person borrowing } \\
\text { groups }\end{array}$ & $(0.537)$ & $(0.532)$ & $(0.554)$ & $(0.551)$ & $(0.546)$ & $(0.582)$ \\
\hline No RD or DD two person & 0.018 & 0.021 & 0.021 & 0.021 & 0.024 & 0.024 \\
\hline borrowing groups & $(0.024)$ & $(0.024)$ & $(0.027)$ & $(0.024)$ & $(0.024)$ & $(0.026)$ \\
\hline Length of loan (weeks) & & & & -0.001 & -0.001 & -0.001 \\
\hline & & & & $(0.001)$ & $(0.001)$ & $(0.001)$ \\
\hline Interest rate & & & & -0.166 & -0.161 & -0.149 \\
\hline (annualized) & & & & $(0.121)$ & $(0.125)$ & $(0.151)$ \\
\hline Group size & & & & -0.001 & -0.001 & -0.001 \\
\hline & & & & $(0.001)$ & $(0.001)$ & $(0.001)$ \\
\hline Loan size (000s pesos) & & & & $0.001^{*}$ & $0.001^{*}$ & $0.001^{* *}$ \\
\hline & & & & $(0.000)$ & $(0.000)$ & $(0.000)$ \\
\hline Borrower age & & & & -0.000 & -0.000 & -0.000 \\
\hline & & & & $(0.000)$ & $(0.000)$ & $(0.000)$ \\
\hline Borrower is male & & & & 0.002 & 0.001 & 0.001 \\
\hline & & & & $(0.004)$ & $(0.003)$ & $(0.003)$ \\
\hline Borrower's tenure with & & & & -0.000 & -0.000 & -0.000 \\
\hline bank & & & & $(0.000)$ & $(0.000)$ & $(0.000)$ \\
\hline Branch Fixed Effect & Yes & Yes & Yes & Yes & Yes & Yes \\
\hline Year Fixed Effect & No & Yes & Yes & No & Yes & Yes \\
\hline Branch-year Fixed Effect & No & No & Yes & No & No & Yes \\
\hline Dep.var. mean & 0.046 & 0.046 & 0.046 & 0.046 & 0.046 & 0.046 \\
\hline R-squared & 0.059 & 0.069 & 0.097 & 0.064 & 0.073 & 0.103 \\
\hline Observations & 22555 & 22555 & 22555 & 22555 & 22555 & 22555 \\
\hline
\end{tabular}

Notes: The dependent variable is an indicator variable equal to one if the loan was defaulted upon. The sample comprises all loans overseen by loan officers who oversaw at least one two person borrowing group loan. Borrowing groups comprising two members are excluded to avoid a mechanical relationship between the left hand side and right hand side. Because the variables of interest are at the loan officer level, each observation is weighted by the number of two person borrowing groups the loan officer oversaw and the standard errors (reported in the parentheses) are clustered at the loan officer level. Stars indicate statistical significance: $* \mathrm{p}<.10 * * \mathrm{p}<.05 * * * \mathrm{p}<.01$. 
Table 4: Structural Estimation Results

\begin{tabular}{|c|c|c|c|c|c|c|}
\hline \multirow[b]{2}{*}{ Returns to Borrowing } & \multirow[b]{2}{*}{ Est. Value } & \multirow[b]{2}{*}{ Std. Error } & \multirow[b]{2}{*}{$5 \%$} & \multicolumn{2}{|c|}{ Confidence interval } & \multirow[b]{2}{*}{$95 \%$} \\
\hline & & & & $10 \%$ & $90 \%$ & \\
\hline $\begin{array}{l}\text { Average Returns (net of princi- } \\
\text { pal and interest of loan) }\end{array}$ & 0.23 & 0.092 & 0.222 & 0.227 & 0.277 & 0.501 \\
\hline $\begin{array}{l}\text { Implied Annual Returns (gross } \\
\text { of interest of loan) }\end{array}$ & $100.0 \%$ & 0.196 & $97.89 \%$ & $99.32 \%$ & $111.13 \%$ & $159.61 \%$ \\
\hline Standard Deviation of Returns & 0.24 & 0.059 & 0.232 & 0.236 & 0.270 & 0.387 \\
\hline Correlation of Returns & -0.44 & 0.106 & -0.440 & -0.440 & -0.331 & -0.165 \\
\hline Discount Factor & 0.91 & 0.083 & 0.725 & 0.850 & 0.910 & 0.910 \\
\hline
\end{tabular}

\section{Group liability}

\begin{tabular}{|c|c|c|c|c|c|c|}
\hline $\begin{array}{l}\text { Estimated optimal group liabil- } \\
\text { ity }\end{array}$ & 0.98 & 0.258 & 0.124 & 0.484 & 0.998 & 1.000 \\
\hline Average loan officer penalty & 0.89 & 0.026 & 0.879 & 0.881 & 0.926 & 0.943 \\
\hline $\begin{array}{l}\text { Percentage of loan officers for } \\
\text { which penalty induces strategic } \\
\text { default }\end{array}$ & $42 \%$ & 0.290 & $0 \%$ & $33.9 \%$ & $88.7 \%$ & $90.2 \%$ \\
\hline Default rates & Total & $(\mathrm{D}, \mathrm{D})$ & $(\mathrm{D}, \mathrm{R})$ & \multicolumn{2}{|c|}{ Strategic default } & \\
\hline Observed default rate & $3.63 \%$ & $3.44 \%$ & $0.38 \%$ & & & \\
\hline Estimated default rate & $3.63 \%$ & $3.45 \%$ & $0.35 \%$ & \multirow{2}{*}{\multicolumn{2}{|c|}{$\begin{array}{l}<0.001 \% \\
0 \%\end{array}$}} & \\
\hline Optimal default rate & $3.51 \%$ & $3.51 \%$ & $<0.001 \%$ & & & \\
\hline
\end{tabular}

\section{Observations}

Number of two person borrowing groups

7844

Number of loan officers

Notes: This table shows the results from the structural estimation of the returns to borrowing and the loan officer-specific group liabilities. The cost of the repayment of the loan (including interest) is normalized to one. The optimal default probability is the default probability that the model predicts would have occurred given the estimated returns to borrowing if all loan officers had enforced the optimal group liability. Standard errors are calculated using a bootstrap procedure over 600 replications; the confidence interval reports the $5 \%, 10 \%, 90 \%$, and $95 \%$ values of each estimate from the bootstrap procedure. 


\section{A Proofs}

This section provides the proofs to Proposition 1 and Corollary 1.

\section{A.1 Proof of Proposition 1}

This section proves Proposition 1. For easy reference, I restate the equations governing the equilibrium of the model:

$$
V(P)=E\left[R_{i}\right]+\pi_{R, R}(P)(\beta V(P)-I)+\pi_{R, D}(P) \mathbf{1}\{P \leq \beta V(P)-I\}(\beta V(P)-I-P),
$$

where the probability that both borrowers can repay can be written as:

$$
\begin{aligned}
\pi_{R, R}(P) \equiv & \operatorname{Pr}\left\{R_{i} \geq I \cap R_{g(i)} \geq I\right\}+\operatorname{Pr}\left\{R_{i} \geq 2 I-R_{g(i)} \cap I-T^{*}(P) \leq R_{g(i)} \leq I\right\} \\
& +\operatorname{Pr}\left\{R_{g(i)} \geq 2 I-R_{i} \cap I-T^{*}(P) \leq R_{i} \leq I\right\},
\end{aligned}
$$

and the probability that $i$ repays and $g(i)$ defaults is:

$$
\pi_{R, D}(P) \equiv \operatorname{Pr}\left\{R_{i} \geq I+T^{*}(P) \cap R_{g(i)} \leq I-T^{*}(P)\right\},
$$

where the maximum transfers $T^{*}(P)$ are:

$$
T^{*}(P)=\min \{P, \beta V(P)-I\} .
$$

In what follows, is proves easier to consider the continuous function:

$$
\tilde{V}(P)=E\left[R_{i}\right]+\tilde{\pi}_{R, R}(P)(\beta \tilde{V}(P)-I)+\tilde{\pi}_{R, D}(P)(\beta \tilde{V}(P)-I-P),
$$

where $\tilde{\pi}_{R, R}(P)$ and $\tilde{\pi}_{R, D}(P)$ are analogous to $\pi_{R, R}(P)$ and $\pi_{R, D}(P)$, except that the transfers are given by $\tilde{T}^{*}(P)=P$ (that is, the tilde equations ignore the possibility of strategic default). Note that when $P \leq \beta \tilde{V}(P)-I$, then $\tilde{V}(P)=V(P)$, i.e. as long as strategic default is not optimal, then the two value functions coincide.

The following three subsections prove each one of the parts of Proposition 1.

\section{A.1.1 $P^{*}$ exists and is strictly positive.}

To see that $P^{*}$ exists and is strictly positive, I use the intermediate value theorem.

From equations $(6),(7),(8)$, and $(9)$, when there is no group liability (i.e. $P=0$ ), then:

$$
\beta \tilde{V}(0)-I=\frac{\beta E\left[R_{i}\right]-I}{1-\beta \operatorname{Pr}\left\{R_{i} \geq I\right\}} \geq 0
$$

Furthermore, since $\pi_{R, R}(P)+\pi_{R, D}(P) \leq 1$, then for all $P>0$ :

$$
\beta \tilde{V}(P)-I \leq \frac{\beta E\left[R_{i}\right]-I}{1-\beta}
$$


Define the function $G(P)=\beta \tilde{V}(P)-I-P$. Note that if $G(P)=0$, then $P=\beta \tilde{V}(P)-I$. From above, $G(0) \geq 0, G\left(\frac{\beta E\left[R_{i}\right]-I}{1-\beta}\right) \leq 0$ and from equation $(9), G(\cdot)$ is continuous. Hence, by the intermediate value theorem, there exists a $P \in\left[0, \frac{\beta E\left[R_{i}\right]-I}{1-\beta}\right]$ such that $P=\beta \tilde{V}(P)-I$. Since $\tilde{V}(P)=V(P)$ if $P=\beta \tilde{V}(P)-I$, this implies that there exists a $P$ such that $P=\beta V(P)-I$. Because $\beta V(P)-I>0$ from equation $(2), P^{*}$ is strictly positive. Note that $P^{*}$ may exceed $I$, i.e. full liability may be optimal.

\section{A.1.2 If Assumption A.1. holds, then the $P^{*}$ is unique.}

To see that $P^{*}$ is unique, I rely on a contradiction argument. Suppose that $P^{*}$ is not unique, i.e. there exists $P_{1}<P_{2}$ such that $P_{1}=\beta V\left(P_{1}\right)-I$ and $P_{2}=\beta V\left(P_{2}\right)-I$.

If we define the function $G(P)=\beta \tilde{V}(P)-I-P$, then this implies that $G\left(P_{1}\right)=0$ and $G\left(P_{2}\right)=0$. From equation (5), we have:

$$
\begin{gathered}
\tilde{V}\left(P_{1}\right)=E\left[R_{i}\right]+\pi_{R, R}\left(P_{1}\right)\left(\beta \tilde{V}\left(P_{1}\right)-I\right) \Longrightarrow \beta \tilde{V}\left(P_{1}\right)-I=\frac{\beta E\left[R_{i}\right]-I}{1-\beta \pi_{R, R}\left(P_{1}\right)} \\
\tilde{V}\left(P_{2}\right)=E\left[R_{i}\right]+\pi_{R, R}\left(P_{2}\right)\left(\beta \tilde{V}\left(P_{2}\right)-I\right) \Longrightarrow \beta \tilde{V}\left(P_{2}\right)-I=\frac{\beta E\left[R_{i}\right]-I}{1-\beta \pi_{R, R}\left(P_{2}\right)} .
\end{gathered}
$$

Since $P_{1}=\beta V\left(P_{1}\right)-I$ and $P_{2}=\beta V\left(P_{2}\right)-I$, we have $P_{1} /\left(\beta V\left(P_{1}\right)-I\right)=P_{2} /\left(\beta V\left(P_{2}\right)-I\right)$, or equivalently:

$$
P_{1}\left(1-\beta \pi_{R, R}\left(P_{1}\right)\right)=P_{2}\left(1-\beta \pi_{R, R}\left(P_{2}\right)\right) .
$$

Define the function $H(P) \equiv P\left(1-\beta \pi_{R, R}(P)\right)$. Since $H\left(P_{1}\right)=H\left(P_{2}\right)$, from Rolle's theorem, there must exist a $\tilde{P} \in\left[P_{1}, P_{2}\right]$ such that $H^{\prime}(\tilde{P})=0$. To prove the contradiction, I show that $H^{\prime}(\tilde{P})>0$ for all $\tilde{P} \in\left[P_{1}, P_{2}\right]$. Differentiating $H(P)$ yields:

$$
H^{\prime}(P)=1-\beta\left(\pi_{R, R}(P)+\frac{\partial \pi_{R, R}(P)}{\partial P} P\right)
$$

so that:

$$
H^{\prime}(P)>0 \Longleftrightarrow \pi_{R, R}(P)+\frac{\partial \pi_{R, R}(P)}{\partial P} P<\frac{1}{\beta}
$$

From equation (6), $\pi_{R, R}(P)=A+2 B(P)$, where $A \equiv \operatorname{Pr}\left\{R_{i} \geq I \cap R_{g(i)} \geq I\right\}$ and $B(P) \equiv \operatorname{Pr}\left\{R_{i} \geq 2 I-R_{g(i)} \cap I-P \leq R_{g(i)} \leq I\right\}$ (where I have imposed symmetry), so that:

$$
\pi_{R, R}(P)+\frac{\partial \pi_{R, R}(P)}{\partial P} P=2 B^{\prime}(P) P+\pi_{R, R}(P)
$$

Now we bound things. $\pi_{R, R}(P)$ is bounded above by $C \equiv \operatorname{Pr}\left\{R_{i}+R_{g(i)} \geq 2 I\right\}$, so that:

$$
P \frac{\partial}{\partial P} \pi_{R, R}(P)+\pi_{R, R}(P) \leq 2 B^{\prime}(P) P+C
$$


It is immediately evident that $B(P)$ is increasing. I also claim $B(P)$ is concave, which I verify below. Then by the mean value theorem, we have:

$$
B(0)+B^{\prime}(P) P<B(P) \Longleftrightarrow B^{\prime}(P) P<B(P)-B(0),
$$

so that

$$
P \frac{\partial}{\partial P} \pi_{R, R}(P)+\pi_{R, R}(P) \leq 2 B^{\prime}(P) P+C<2 B(P)-2 B(0)+C
$$

Finally, since $B(0)=0$ and $2 B(P)$ is bounded above by $D \equiv 2 \operatorname{Pr}\left\{R_{i} \geq 2 I-R_{g(i)} \cap R_{g(i)} \leq\right.$ $I\}$, we have:

$$
P \frac{\partial}{\partial P} \pi_{R, R}(P)+\pi_{R, R}(P) \leq 2 B^{\prime}(P) P+C<2(B(P)-B(0))+C \leq C+D
$$

As a result, if

$$
\operatorname{Pr}\left\{R_{i}+R_{g(i)} \geq 2 I\right\}+2 \operatorname{Pr}\left\{R_{i} \geq 2 I-R_{g(i)} \cap R_{g(i)} \leq I\right\}<\frac{1}{\beta}
$$

i.e. the event of the total group returns exceeding the total group repayment costs cannot occur too much more often than the either both group members being able to afford to repay their own loan or the total group returns being insufficient to cover the total group repayment costs, then $P^{*}=\beta V\left(P^{*}\right)-I$ is unique.

Let $f\left(R_{i}, R_{g(i)}\right)$ be the probability density function governing the joint distribution of returns of $R_{i}$ and $R_{g(i)}$. To see that $B(P)$ is concave, note that:

$$
B(P) \equiv \operatorname{Pr}\left\{R_{i} \geq 2 I-R_{g(i)} \cap I-P \leq R_{g(i)} \leq I\right\}=\int_{I-P}^{I} \int_{2 I-R_{g(i)}}^{\infty} f\left(R_{i}, R_{g(i)}\right) d R_{i} d R_{g(i)}
$$

so that by Leibniz rule:

$$
B^{\prime}(x)=\int_{I+P}^{\infty} f\left(R_{i}, I-x\right) d R_{i}>0
$$

Hence, $B^{\prime}(P)$ is equal to $\operatorname{Pr}\left\{R_{i}>I+P \cap R=I-P\right\}>0 . B^{\prime \prime}(P)=\frac{\partial}{\partial P} \int_{I+P}^{\infty} f\left(R_{i}, I-P\right) d R_{i}=$ $-f(I+P, I-P)$, which is negative because $f(\cdot)$ is a probability density function.

\section{A.1.3 If Assumption A.2 holds, $P^{*}$ minimizes default rates.}

Define the repayment rate to be $\pi(P)$. Note that:

$$
\pi(P)=\pi_{R, R}(P)+\mathbf{1}\{P \leq \beta V(P)-I\} \pi_{R, D}(P)
$$

since if $P>\beta V(P)-I$, the borrower will find it optimal to strategically default.

If $P>\beta V(P)-I$, then I claim that $\pi(P)=\tilde{\pi}$, where $\tilde{\pi}$ is a constant. To see this, note that when $P>\beta V(P)-I$ equation (5) yields the following expression for the value of 
borrowing:

$$
V=\frac{E\left[R_{i}\right]-\pi_{R, R}(P) I}{1-\beta \pi_{R, R}(P)},
$$

where from expressions (6) and (8):

$$
\begin{aligned}
\pi_{R, R}(P)= & \operatorname{Pr}\left\{R_{i} \geq I \cap R_{g(i)} \geq I\right\}+\operatorname{Pr}\left\{R_{i} \geq 2 I-R_{g(i)} \cap I-\frac{\beta E\left[R_{i}\right]-I}{1-\beta \pi_{R, R}(P)} \leq R_{g(i)} \leq I\right\} \\
& +\operatorname{Pr}\left\{R_{g(i)} \geq 2 I-R_{i} \cap I-\frac{\beta E\left[R_{i}\right]-I}{1-\beta \pi_{R, R}(P)} \leq R_{i} \leq I\right\} .
\end{aligned}
$$

Note that $\pi_{R, R}(P)$ does not depend on $P$, so let $\tilde{\pi} \equiv \pi_{R, R}(P)$. Since if $P>\beta V(P)-I$, from expression (10), the probability of repaying is the probability that both group members repay, then it follows immediately that $\pi(P)=\pi_{R, R}(P)=\tilde{\pi}$ as claimed.

If $P \leq \beta V(P)-I$, then I claim that $\frac{\partial \pi(P)}{\partial P}>0$. Note that if $P \leq \beta V(P)-I$, then $\pi(P)=\pi_{R, R}(P)+\pi_{R, D}(P)$. Combining expressions (6), (7), and (8) yields:

$\pi(P)=\operatorname{Pr}\left\{R_{i} \geq I\right\}+\operatorname{Pr}\left\{R_{g(i)} \geq 2 I-R_{i} \cap I-P \leq R_{i} \leq I\right\}-\operatorname{Pr}\left\{R_{g(i)}<2 I-R_{i} \cap I \leq R_{i} \leq I+P\right\}$, so that $\frac{\partial \pi(P)}{\partial P}>0$ if and only if:

$$
\frac{\partial}{\partial P} \operatorname{Pr}\left\{R_{g(i)} \geq 2 I-R_{i} \cap I-P \leq R_{i} \leq I\right\}>\frac{\partial}{\partial P} \operatorname{Pr}\left\{R_{g(i)}<2 I-R_{i} \cap I \leq R_{i} \leq I+P\right\},
$$

which is assumed.

Since $\frac{\partial \pi(P)}{\partial P}>0$ for all $P$ such that $P \leq \beta V(P)-I$, it follows that the repayment rate is maximized in this range when $P=\beta V(P)-I$. When $P=\beta V(P)-I$, we have:

$$
\pi(P)=\tilde{\pi}+\pi_{R, D}(P) \geq \tilde{\pi},
$$

where:

$$
V=\frac{E\left[R_{i}\right]-\tilde{\pi} I}{1-\beta \tilde{\pi}}
$$

and:

$$
\begin{aligned}
\pi_{R, D}(P)= & \operatorname{Pr}\left\{R_{i} \geq I\right\}-\operatorname{Pr}\left\{R_{i} \geq I \cap R_{g(i)} \geq I\right\}-\operatorname{Pr}\left\{R_{i} \geq 2 I-R_{g(i)} \cap I-P \leq R_{g(i)} \leq I\right\} \\
& -\operatorname{Pr}\left\{R_{g(i)}<2 I-R_{i} \cap I \leq R_{i} \leq I+T^{*}(P)\right\} \geq 0 .
\end{aligned}
$$

Note that the value function to the borrower is identical to the case when $P>\beta V(P)-$ $I$ above, but the repayment probability is (weakly) greater since the borrower repays an additional $\pi_{R, D}$ fraction of the time. As a result, when $P=\beta V-I$, the repayment probability $\pi(P)$ is maximized. 


\section{A.2 Proof of Corollary 1}

\section{A.2.1 If Assumption A.2 holds, then for any fixed interest rate, $P^{*}$ maximizes lender revenue.}

I now choose the loan amount as the numeraire, so that the amount to be repaid is $I=1+r$, where $r$ is the interest rate. Each firm takes $r$ as fixed and earns per-borrowing group revenue $\rho$ :

$\rho(P)=2\left(\left(\pi_{R, R}(P)+\mathbf{1}\{P \leq \beta V(P)-I\} \pi_{R, D}(P)\right)(1+r)+\mathbf{1}\{P \leq \beta V(P)-I\} \pi_{R, D}(P) P-1\right)$.

Clearly all $\tilde{P}>P^{*}$ achieve less revenue than $P^{*}$, as the lender receives no revenue from either the borrower who cannot repay or the borrower who strategically defaults. It remains to show that $\rho\left(P^{*}\right) \geq \rho(\tilde{P})$ for all $\tilde{P}<P^{*}$. To show this, I show that for all $P \leq P^{*}$, $\frac{\partial}{\partial P} \rho(P)>0$. Note that:

$$
\begin{aligned}
\frac{1}{2} \frac{\partial}{\partial P} \rho(P)= & \pi_{R, D}(P)+(1+r-P) \frac{\partial}{\partial P} \operatorname{Pr}\left\{R_{g(i)} \geq 2 I-R_{i} \cap I-P \leq R_{i} \leq I\right\} \\
& -(1+r-P) \frac{\partial}{\partial P} \operatorname{Pr}\left\{R_{g(i)}<2 I-R_{i} \cap I \leq R_{i} \leq I+T^{*}(P)\right\}
\end{aligned}
$$

Since $P<1+r$ and by assumption $\frac{\partial}{\partial P} \operatorname{Pr}\left\{R_{g(i)} \geq 2 I-R_{i} \cap I-P \leq R_{i} \leq I\right\}>\frac{\partial}{\partial P} \operatorname{Pr}\left\{R_{g(i)}<\right.$ $\left.2 I-R_{i} \cap I \leq R_{i} \leq I+T^{*}(P)\right\}$, we have:

$$
\frac{\partial}{\partial P} \rho(P)>2 \pi_{R, D}(P) \geq 0
$$

as claimed.

\section{A.2.2 If Assumption A.2 holds and lenders earn zero profits, $P^{*}$ maximizes the value of borrowing.}

Again, rather than normalizing the amount to be repaid to one, let me normalize the loan amount to 1 and let the equilibrium interest rate be $r^{*}$ so that $I^{*}=1+r^{*}$, where the star notation indicates that the amount is determined in equilibrium by a zero profit condition. Each firm takes $r^{*}$ as fixed and earns per-borrowing group revenue $\rho$ :

$\rho(P)=2\left(\left(\pi_{R, R}(P)+\mathbf{1}\left\{P \leq \beta V(P)-I^{*}\right\} \pi_{R, D}(P)\right)\left(1+r^{*}\right)+\mathbf{1}\left\{P \leq \beta V(P)-I^{*}\right\} \pi_{R, D}(P) P-1\right)$

The equilibrium interest rate $r^{*}(P)$ ensures that the profits of each lender are equal to zero:

$$
\rho(P)=0 \Longleftrightarrow 1+r^{*}(P)=\frac{1-\mathbf{1}\left\{P \leq \beta V(P)-I^{*}\right\} \pi_{R, D}(P) P}{\pi_{R, R}(P)+\mathbf{1}\left\{P \leq \beta V(P)-I^{*}\right\} \pi_{R, D}(P)} .
$$

From equation (5), we have:

$V(P)=\frac{E\left[R_{i}\right]-\left(\pi_{R, R}(P)+\pi_{R, D}(P) \mathbf{1}\left\{P \leq \beta V(P)-I^{*}\right\}\right) I^{*}-\pi_{R, D}(P) \mathbf{1}\left\{P \leq \beta V(P)-I^{*}\right\} P}{1-\beta\left(\pi_{R, R}(P)+\pi_{R, D}(P) \mathbf{1}\left\{P \leq \beta V(P)-I^{*}\right\}\right)}$ 
Substituting in the equilibrium interest rate $I^{*}=1+r^{*}(P)$ yields:

$$
V(P)=\frac{E\left[R_{i}\right]-1}{1-\beta\left(\pi_{R, R}(P)+\pi_{R, D}(P) \mathbf{1}\left\{P \leq \beta V(P)-\left(1+r^{*}(P)\right)\right\}\right)}
$$

Hence maximizing borrower welfare requires maximizing $\pi_{R, R}(P)+\pi_{R, D}(P) \mathbf{1}\{P \leq \beta V(P)-$ $I^{*}$, i.e. it requires maximizing the probability of repayment. From Proposition 1 , this occurs at $P^{*}$, as claimed. 


\section{Online Appendix (not for publication)}

\section{B Model extensions}

This section extends the model to incorporate several additional characteristics of microfinance borrowing, namely collateral, within-group heterogeneity in loan size, social sanctions, and groups with more than two members. The implication that a partial liability which maximizes group transfers without inducing strategic default minimizes default rates remains true in all extensions.

\section{B.1 Incorporating collateral}

Suppose that borrowers are required to put down collateral $C \leq I$ in order to borrow which the bank may keep if the borrower fails to repay. Without loss of generality, assume that $i$ is considering whether or not to make a transfer $T$ to $g(i)$ to allow $g(i)$ to repay her loan. Individual $i$ will make the transfer if the value of doing so exceeds the maximum of letting $g(i)$ default and either repaying or defaulting herself:

$$
R_{i}+\beta V-I-T \geq \max \left\{R_{i}+\beta V-I-P, R_{i}-C\right\}
$$

As a result, the maximum transfer that $i$ is willing to make is the minimum of the penalty she incurs when $g(i)$ defaults and the present discounted value of continuing to borrow less plus the value of the collateral she would have forfeited if she were to have defaulted:

$$
T^{*}=\min \{P, \beta V-I+C\}
$$

Since individual $i$ will choose to strategically default if and only if $P>\beta V-I+C$, the optimal liability is $P^{*}=\beta V-I+C$. Hence, the greater the amount of collateral that the bank requires, the higher the group liability (and hence within-group risk sharing) that can be maintained without inducing strategic default, as the cost of strategically defaulting increases in the amount of collateral.

\section{B.2 Within-group heterogeneity in loan size}

Suppose that borrower $i$ has a loan of size $I$ and her group member $g(i)$ has a loan of size $\alpha I$. Let the group liability rate be the same for both borrowers (i.e. each borrower is penalized a fraction $p$ of their group member's loan size if their group member fails to repay). Suppose that $g(i)$ is unable to repay and $i$ is considering whether to make a transfer to $g(i)$. Borrower $i$ will make the transfer if and only if her value of making the transfer exceeds the maximum of repaying and allowing her group member to default or defaulting herself:

$$
R_{i}-T+\beta V_{i}-I \geq \max \left\{R_{i}-p \alpha I+\beta V-I, R_{i}\right\}
$$

As a result, the maximum transfer $i$ is willing to make to $g(i)$ is:

$$
T_{i}^{*}=\min \left\{p \alpha I, \beta V_{i}-I\right\}
$$


and, as in the basic model, strategic default becomes optimal when $\beta V_{i}-I<p \alpha I$. Hence, the optimal group liability that maximizes $i^{\prime} s$ transfers without inducing her to strategically default is $p_{i}^{*}=\beta \frac{V_{i}}{\alpha I}-1$. By a similar logic, if $i$ is unable to repay, $g(i)$ will be willing to transfer up to $T_{g(i)}^{*}=\min \left\{p I, \beta V_{g(i)}-\alpha I\right\}$, and will strategically default when $\beta V_{g(i)}-\alpha I<p I$, so that the optimal group liability that maximizes $g(i)$ 's transfers without incentivizing strategic default is $p_{g(i)}^{*}=\beta \frac{V_{g(i)}}{I}-\alpha$. Hence, as in the basic model, any liability below $\min \left\{p_{i}^{*}, p_{g(i)}^{*}\right\}$ or above $\max \left\{p_{i}^{*}, p_{g(i)}^{*}\right\}$ is suboptimal.

Calculating the value functions for $i$ and $g(i)$ and substituting this into the optimal group liabilities yields expressions for each group members optimal liabilities (where I retain the assumption of zero expected net transfers):

$$
\begin{gathered}
p_{i}^{*}=\frac{\beta}{\alpha} \frac{\frac{E\left[R_{i}\right]}{I}-\pi_{R, R}}{1-\beta \pi_{R, R}}-1 \\
p_{g(i)}^{*}=\beta \frac{\frac{E\left[R_{g(i)}\right]}{I}-\pi_{R, R} \alpha}{1-\beta \pi_{R, R}}-\alpha
\end{gathered}
$$

If the expected returns to borrowing are a constant fraction of the amount (i.e. $\frac{E\left[R_{g(i)}\right]}{I}=$ $\left.\alpha \frac{E\left[R_{i}\right]}{I}\right)$, then:

$$
p_{g(i)}^{*}=\alpha^{2} p_{i}^{*}+(\alpha-1)
$$

If $\alpha>1$ (i.e. $g(i)$ has a larger loan than $i$ ), then $g(i)$ can incur a higher group liability rate than $i$ for two reasons: first, her value of borrowing is greater since expected returns are proportional to the loan amount; second, the cost of her group member defaulting is lower since she is penalized a fraction of her group member's loan, which is smaller than her own.

\section{B.3 Social sanctions}

Suppose there is an additional stage (Stage 4) of the basic game where borrowers can choose to inflict a utility cost (a "social sanction") $s \in[0, S]$ on their group member at zero cost to themselves. Borrowers will find it optimal to inflict the maximum social sanction $S$ on their group members in the event that the group member does not make a transfer that she is able to afford. While social sanctions will increase the amount of within-group risk sharing, because an individual can inflict a social sanction regardless of whether their group member repays, social sanctions will not directly affect the optimal group liability.

To see this, suppose that $i$ is considering whether or not to make a transfer $T$ to $g(i)$. Individual $i$ will make the transfer if and only if the value of making the transfer exceeds the maximum of the value of not making the transfer, incurring the social sanction, and either repaying or strategically defaulting:

$$
R_{i}+\beta V-I-T \geq \max \left\{R_{i}+\beta V-I-P-S, R_{i}-S\right\}
$$

As a result, the maximum transfer that $i$ is willing to make is:

$$
T^{*}=S+\min \{\beta V-I, P\},
$$


so that the maximum transfer is increasing monotonically in the maximum social sanction. Individual $i$ will choose to strategically default if and only if $P>\beta V-I$. Hence, as in the basic model, the optimal group liability is $P^{*}=\beta V-I$, which depends on the social sanction only to the extent that the value of borrowing $V$ increases in $S$ due to the increased within-group risk sharing.

\section{B.4 Groups with more than two members}

Suppose there are $N>2$ members in a group. As in the basic model, no borrower will be willing to transfer more than $\beta V(P)-I$ (the value of remaining eligible to borrow in the future) to another group member. Suppose that $n$ individuals are facing shortcomings and in need of transfers. With group liability $P$, the group faces a total penalty of $n P$. In what follows, I assume that groups can credibly threaten individual members with having to incur the total penalty themselves if they do not participate in the intra-group risk sharing so that any borrower would be willing to transfer at most $T_{n}^{*}=\min \{\beta V(P)-I, n P\} .{ }^{25}$ Given these transfers, however, if $n$ individuals actually default, I assume the remaining repaying members split the liability penalty equally. ${ }^{26}$

Given this set-up, I show two things: first, that the model predicts a U-shaped relationship between group liability and default rates and the optimal group liability is no greater that $\beta V-I$; second, if there is free entry, the welfare of a borrower is maximized when the probability of default is minimized.

As in the basic model, the group liability affects the probability of repayment in two ways: first, higher group liabilities incentivize greater within-group risk sharing; second, higher group liabilities incentivize strategic default, as the maximum number of group members a borrower is willing to let default before strategically defaulting herself is $k(P)=$ $\left\lfloor\left(\frac{\beta V-I}{\beta V-I+P}\right) N\right\rfloor$. Since transfers are maximized at the fixed point $P=\beta V(P)-I$ for all $n$, the optimal group liability is no higher than the present discounted value of continuing to borrow: $P^{*} \leq \beta V\left(P^{*}\right)-I$. Whether or not $P^{*}$ is strictly below $\beta V\left(P^{*}\right)-I$, however, depends on the relative importance of strategic default and within-group risk sharing, which will vary depending on the distribution of returns. As $P$ increases, within-group transfers increase up to $P=\beta V(P)-I$, lowering the default rate. However, $k(P)$ declines, causing discontinuous increases in strategic default rates, resulting in a U-shaped relationship between group liability and default rates. Intuitively, the more group members who are forced to default because of insufficient returns, the greater the incentive each of the remaining group members has to strategically default, as the larger group liability penalty is shared across a fewer number of borrowers.

I now show that if there is free entry, the welfare of a borrower is maximized when the probability of default is minimized. Let $\pi_{n}$ be the probability that $n$ group members default

\footnotetext{
${ }^{25}$ Because this assumption maximizes the amount of intra-group risk-sharing, both borrowers and loan officers would have an incentive to commit to such a penalty scheme ex-ante.

${ }^{26} \mathrm{~A}$ more general structure would allow lenders to impose a penalty $f(n, N)$ on each repaying member when $n$ group members default in an $N$. Indeed, it is straightforward to show that as in the two person borrowing group, the optimal penalty structure is $f(n, N)=\beta V(P)-I$. I focus on the case where $f(n, N)=\frac{n}{N-n} P$ because it seems best reflective of the actual rules of group liability lending, i.e. all repaying members incur an equal penalty of a fraction $P / I$ of the unpaid loans.
} 
(where, for clarity, I do not explicitly note the dependence on model parameters). Normalize the loan amount to one so that $I=1+r$. Then the per borrower profits to the MFI are:

$$
\Pi(p, r)=\frac{1}{N} \sum_{n=0}^{N} \pi_{n}\left(\mathbf{1}\left\{\beta V-(1+r) \geq \frac{n}{N-n} p\right\}(N-n)\left(1+r+\frac{n}{N-n} p\right)-N\right)
$$

With free entry, given a group liability $p$, the interest rate ensures that each MFI earns zero profits:

$$
1+r^{*}(p)=\frac{1-\sum_{n=0}^{N} \pi_{n} \mathbf{1}\left\{\beta V-(1+r) \geq \frac{n}{N-n} p\right\} \frac{n}{N} p}{\sum_{n=0}^{N} \pi_{n} \mathbf{1}\left\{\beta V-(1+r) \geq \frac{n}{N-n} p\right\}\left(\frac{N-n}{N}\right)}
$$

Using the fact that if $n$ group members default with probability $\pi_{n}$, the probability any particular group member repays is $\frac{N-n}{N}$, the borrowers value function is:

$$
V=E\left[\frac{R_{i}}{I}\right]+\sum_{n=0}^{N} \pi_{n}\left(\frac{N-n}{N}\right) \max \left\{\beta V-(1+r)-\frac{n}{N-n} p, 0\right\}
$$

which is equivalent to:

$$
V=\frac{E\left[\frac{R_{i}}{I}\right]-I \sum_{n=0}^{N-1} \pi_{n}\left(\frac{N-n}{N}\right) \mathbf{1}\left\{\beta V-I \geq \frac{n}{N-n} p\right\}-\sum_{n=0}^{N-1} \pi_{n} \mathbf{1}\left\{\beta V-I \geq \frac{n}{N-n} p\right\} \frac{n}{N} p}{1-\beta \sum_{n=0}^{N-1} \pi_{n}\left(\frac{N-n}{N}\right) \mathbf{1}\left\{\beta V-I \geq \frac{n}{N-n} p\right\}}
$$

Substituting in the zero profit interest rate given in equation (11) into the borrower value function given in equation (13) yields an expression for welfare:

$$
V(p)=\frac{E\left[R_{i}\right]-I}{1-\beta \sum_{n=0}^{N-1} \pi_{n}\left(\frac{N-n}{N}\right) \mathbf{1}\left\{\beta V-I \geq \frac{n}{N-n} P\right\}} .
$$

As in the basic model with two borrowers, welfare is maximized by maximizing the probability the individual borrower repays. 


\section{Additional Tables and Figures}

Figure 8: Nonparametric relationship composition of two-member borrowing group defaults and level of default in borrowing groups with three or more members

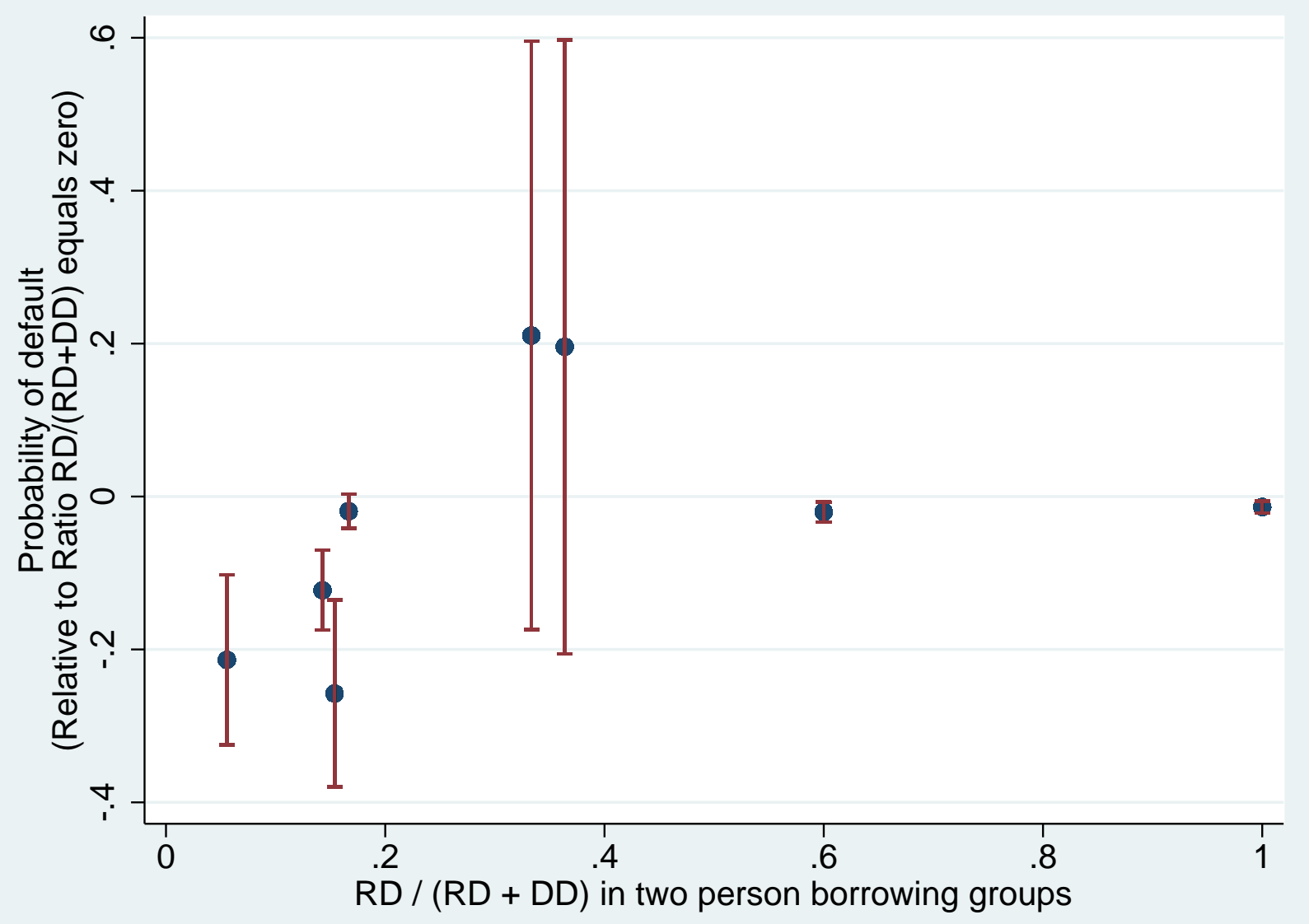

Notes: This figure shows the non-parametric relationship between the fraction of defaulting two member borrowing groups where one group member repays $\left(f r a c R D_{l}\right)$ for a particular loan officer and the default rates that loan officer achieves in all other (three or more member) borrowing groups. The regression is the fully non-parametric version of equation (3) and Table 3, where all values of $f r a c R D_{l}$ are included as dummy variables and the coefficients are estimated separately. The excluded category are those loan officers for which $f r a c R D_{l}=0$ (but who did oversee two member loans in which default occurred). The standard errors (reported in the parentheses) are clustered at the loan officer level and the bars report the implied 2.5\%/97.5\% confidence intervals. 
Table 5: Evidence of Optimal Partial Liability: Alternative ratio measure

\begin{tabular}{|c|c|c|c|c|c|c|}
\hline & (1) & (2) & (3) & (4) & (5) & (6) \\
\hline $\mathrm{RD} /(1+\mathrm{DD})$ in two & $0.028^{* *}$ & $0.027^{*}$ & $0.029^{* *}$ & $0.028^{* *}$ & $0.026^{*}$ & $0.029^{* *}$ \\
\hline person borrowing groups & $(0.013)$ & $(0.014)$ & $(0.013)$ & $(0.013)$ & $(0.013)$ & $(0.013)$ \\
\hline No RD two person & $0.059^{* *}$ & $0.059^{* *}$ & $0.063^{* *}$ & $0.060^{* *}$ & $0.058^{* *}$ & $0.064^{* *}$ \\
\hline borrowing groups & $(0.024)$ & $(0.025)$ & $(0.025)$ & $(0.024)$ & $(0.024)$ & $(0.025)$ \\
\hline $\begin{array}{l}\text { Probability of default in } \\
\text { two person borrowing } \\
\text { groups }\end{array}$ & $\begin{array}{l}1.549^{* * * *} \\
(0.399)\end{array}$ & $\begin{array}{l}1.559^{* * *} \\
(0.395)\end{array}$ & $\begin{array}{l}1.521^{* * *} \\
(0.394)\end{array}$ & $\begin{array}{l}1.468^{* * *} \\
(0.420)\end{array}$ & $\begin{array}{l}1.474^{* * *} \\
(0.423)\end{array}$ & $\begin{array}{l}1.450^{* * * *} \\
(0.439)\end{array}$ \\
\hline Length of loan (weeks) & & & & $\begin{array}{l}-0.001 \\
(0.001)\end{array}$ & $\begin{array}{l}-0.001 \\
(0.001)\end{array}$ & $\begin{array}{l}-0.001 \\
(0.001)\end{array}$ \\
\hline Interest rate & & & & -0.160 & -0.153 & -0.143 \\
\hline (annualized) & & & & $(0.121)$ & $(0.126)$ & $(0.152)$ \\
\hline Group size & & & & $\begin{array}{l}-0.001 \\
(0.001)\end{array}$ & $\begin{array}{l}-0.001 \\
(0.001)\end{array}$ & $\begin{array}{l}-0.001 \\
(0.001)\end{array}$ \\
\hline Loan size (000s pesos) & & & & $\begin{array}{l}0.001^{*} \\
(0.000)\end{array}$ & $\begin{array}{l}0.001^{*} \\
(0.000)\end{array}$ & $\begin{array}{l}0.001^{* *} \\
(0.000)\end{array}$ \\
\hline Borrower age & & & & $\begin{array}{l}-0.000 \\
(0.000)\end{array}$ & $\begin{array}{l}-0.000 \\
(0.000)\end{array}$ & $\begin{array}{l}-0.000 \\
(0.000)\end{array}$ \\
\hline Borrower is male & & & & $\begin{array}{l}0.002 \\
(0.004)\end{array}$ & $\begin{array}{l}0.001 \\
(0.003)\end{array}$ & $\begin{array}{l}0.001 \\
(0.003)\end{array}$ \\
\hline $\begin{array}{l}\text { Borrower's tenure with } \\
\text { bank }\end{array}$ & & & & $\begin{array}{l}-0.000 \\
(0.000)\end{array}$ & $\begin{array}{l}-0.000 \\
(0.000)\end{array}$ & $\begin{array}{l}-0.000 \\
(0.000)\end{array}$ \\
\hline Branch Fixed Effect & Yes & Yes & Yes & Yes & Yes & Yes \\
\hline Year Fixed Effect & No & Yes & Yes & No & Yes & Yes \\
\hline Branch-year Fixed Effect & No & No & Yes & No & No & Yes \\
\hline Dep.var. mean & 0.046 & 0.046 & 0.046 & 0.046 & 0.046 & 0.046 \\
\hline R-squared & 0.058 & 0.069 & 0.097 & 0.064 & 0.073 & 0.102 \\
\hline Observations & 22555 & 22555 & 22555 & 22555 & 22555 & 22555 \\
\hline
\end{tabular}

Notes: The dependent variable is an indicator variable equal to one if the loan was defaulted upon. The sample comprises all loans overseen by loan officers who oversaw at least one two person borrowing group loan. Borrowing groups comprising two members are excluded to avoid a mechanical relationship between the left hand side and right hand side. Because the variables of interest are at the loan officer level, each observation is weighted by the number of two person borrowing groups the loan officer oversaw and the standard errors (reported in the parentheses) are clustered at the loan officer level. Stars indicate statistical significance: $* \mathrm{p}<.10 * * \mathrm{p}<.05 * * * \mathrm{p}<.01$. 
Table 6: Evidence of Optimal Partial Liability: Unweighted observations

\begin{tabular}{|c|c|c|c|c|c|c|}
\hline & (1) & $(2)$ & (3) & $(4)$ & $(5)$ & (6) \\
\hline RD / (RD + DD) in two & 0.127 & 0.118 & $0.165^{*}$ & $0.128^{*}$ & 0.103 & $0.146^{*}$ \\
\hline person borrowing groups & $(0.078)$ & $(0.079)$ & $(0.086)$ & $(0.074)$ & $(0.072)$ & $(0.076)$ \\
\hline No RD two person & 0.080 & 0.082 & $0.108^{*}$ & 0.078 & 0.072 & $0.094^{*}$ \\
\hline borrowing groups & $(0.049)$ & $(0.053)$ & $(0.055)$ & $(0.049)$ & $(0.052)$ & $(0.050)$ \\
\hline $\begin{array}{l}\text { Probability of default in } \\
\text { two person borrowing } \\
\text { groups }\end{array}$ & $\begin{array}{l}1.956^{* *} \\
(0.962)\end{array}$ & $\begin{array}{l}1.958^{* *} \\
(0.943)\end{array}$ & $\begin{array}{l}2.095^{* *} \\
(0.920)\end{array}$ & $\begin{array}{l}2.005^{* *} \\
(0.970)\end{array}$ & $\begin{array}{l}1.964^{* *} \\
(0.919)\end{array}$ & $\begin{array}{l}2.110^{* *} \\
(0.892)\end{array}$ \\
\hline Length of loan (weeks) & & & & $\begin{array}{l}-0.001 \\
(0.001)\end{array}$ & $\begin{array}{l}0.000 \\
(0.001)\end{array}$ & $\begin{array}{l}0.001 \\
(0.001)\end{array}$ \\
\hline $\begin{array}{l}\text { Interest rate } \\
\text { (annualized) }\end{array}$ & & & & $\begin{array}{l}0.057 \\
(0.169)\end{array}$ & $\begin{array}{l}0.135 \\
(0.207)\end{array}$ & $\begin{array}{l}0.276 \\
(0.294)\end{array}$ \\
\hline Group size & & & & $\begin{array}{l}-0.001 \\
(0.001)\end{array}$ & $\begin{array}{l}-0.002 \\
(0.001)\end{array}$ & $\begin{array}{l}-0.002 \\
(0.002)\end{array}$ \\
\hline Loan size (000s pesos) & & & & $\begin{array}{l}0.000 \\
(0.000)\end{array}$ & $\begin{array}{l}0.000 \\
(0.000)\end{array}$ & $\begin{array}{l}0.000 \\
(0.001)\end{array}$ \\
\hline Borrower age & & & & $\begin{array}{l}-0.000 \\
(0.000)\end{array}$ & $\begin{array}{l}-0.000 \\
(0.000)\end{array}$ & $\begin{array}{l}-0.000 \\
(0.000)\end{array}$ \\
\hline Borrower is male & & & & $\begin{array}{l}0.005 \\
(0.009)\end{array}$ & $\begin{array}{l}0.003 \\
(0.008)\end{array}$ & $\begin{array}{l}0.001 \\
(0.008)\end{array}$ \\
\hline $\begin{array}{l}\text { Borrower's tenure with } \\
\text { bank }\end{array}$ & & & & $\begin{array}{l}-0.000 \\
(0.000)\end{array}$ & $\begin{array}{l}-0.000^{*} \\
(0.000)\end{array}$ & $\begin{array}{l}-0.000 \\
(0.000)\end{array}$ \\
\hline Branch Fixed Effect & Yes & Yes & Yes & Yes & Yes & Yes \\
\hline Year Fixed Effect & No & Yes & Yes & No & Yes & Yes \\
\hline Branch-year Fixed Effect & No & No & Yes & No & No & Yes \\
\hline Dep.var. mean & 0.046 & 0.046 & 0.046 & 0.046 & 0.046 & 0.046 \\
\hline R-squared & 0.103 & 0.128 & 0.173 & 0.105 & 0.133 & 0.180 \\
\hline Observations & 22555 & 22555 & 22555 & 22555 & 22555 & 22555 \\
\hline
\end{tabular}

Notes: The dependent variable is an indicator variable equal to one if the loan was defaulted upon. The sample comprises all loans overseen by loan officers who oversaw at least one two person borrowing group loan. Borrowing groups comprising two members are excluded to avoid a mechanical relationship between the left hand side and right hand side. The standard errors (reported in the parentheses) are clustered at the loan officer level. Stars indicate statistical significance: ${ }^{*} \mathrm{p}<.10 * * \mathrm{p}<.05{ }^{* * *} \mathrm{p}<.01$. 
Table 7: Default Combinations by Loan Officer in Structural Estimation Sample

\begin{tabular}{|c|c|c|c|c|}
\hline Loan Officer & RR Loans & RD Loans & DD Loans & Total number of loans \\
\hline 1 & 776 & 0 & 6 & 782 \\
\hline 2 & 572 & 2 & 10 & 584 \\
\hline 3 & 458 & 0 & 4 & 462 \\
\hline 4 & 388 & 0 & 0 & 388 \\
\hline 5 & 358 & 0 & 18 & 376 \\
\hline 6 & 290 & 2 & 34 & 326 \\
\hline 7 & 254 & 0 & 24 & 278 \\
\hline 8 & 236 & 8 & 14 & 258 \\
\hline 9 & 240 & 6 & 4 & 250 \\
\hline 10 & 208 & 2 & 4 & 214 \\
\hline 11 & 192 & 0 & 16 & 208 \\
\hline 12 & 182 & 2 & 12 & 196 \\
\hline 13 & 188 & 2 & 4 & 194 \\
\hline 14 & 192 & 0 & 0 & 192 \\
\hline 15 & 164 & 0 & 14 & 178 \\
\hline 16 & 178 & 0 & 0 & 178 \\
\hline 17 & 166 & 0 & 10 & 176 \\
\hline 18 & 166 & 0 & 0 & 166 \\
\hline 19 & 162 & 0 & 0 & 162 \\
\hline 20 & 134 & 4 & 22 & 160 \\
\hline 21 & 148 & 2 & 0 & 150 \\
\hline 22 & 142 & 0 & 2 & 144 \\
\hline 23 & 130 & 0 & 2 & 132 \\
\hline 24 & 130 & 0 & 0 & 130 \\
\hline 25 & 124 & 0 & 0 & 124 \\
\hline 26 & 112 & 0 & 0 & 112 \\
\hline 27 & 102 & 0 & 4 & 106 \\
\hline 28 & 94 & 0 & 4 & 98 \\
\hline 29 & 86 & 0 & 4 & 90 \\
\hline 30 & 84 & 0 & 0 & 84 \\
\hline 31 & 72 & 0 & 0 & 72 \\
\hline 32 & 68 & 0 & 0 & 68 \\
\hline 33 & 60 & 0 & 6 & 66 \\
\hline 34 & 58 & 0 & 0 & 58 \\
\hline 35 & 50 & 0 & 4 & 54 \\
\hline 36 & 48 & 0 & 6 & 54 \\
\hline 37 & 50 & 0 & 2 & 52 \\
\hline 38 & 46 & 0 & 6 & 52 \\
\hline 39 & 42 & 0 & 6 & 48 \\
\hline 40 & 38 & 0 & 8 & 46 \\
\hline 41 & 36 & 0 & 0 & 36 \\
\hline 42 & 36 & 0 & 0 & 36 \\
\hline 43 & 30 & 0 & 4 & 34 \\
\hline 44 & 28 & 0 & 4 & 32 \\
\hline 45 & 22 & 0 & 4 & 26 \\
\hline 46 & 26 & 0 & 0 & 26 \\
\hline 47 & 22 & 0 & 0 & 22 \\
\hline 48 & 20 & 0 & 0 & 20 \\
\hline 49 & 18 & 0 & 0 & 18 \\
\hline 50 & 14 & 0 & 2 & 16 \\
\hline 51 & 14 & 0 & 2 & 16 \\
\hline 52 & 16 & 0 & 0 & 16 \\
\hline 53 & 14 & 0 & 0 & 14 \\
\hline 54 & 12 & 0 & 2 & 14 \\
\hline 55 & 12 & 0 & 0 & 12 \\
\hline 56 & 10 & 0 & 0 & 10 \\
\hline 57 & 6 & 0 & 2 & 8 \\
\hline 58 & 6 & 0 & 0 & 6 \\
\hline 59 & 4 & 0 & 0 & 4 \\
\hline 60 & 4 & 0 & 0 & 4 \\
\hline 61 & 4 & 0 & 0 & 4 \\
\hline 62 & 2 & 0 & 0 & 2 \\
\hline Total & 7544 & 30 & 270 & 7,844 \\
\hline
\end{tabular}

Notes: This table shows the frequency of all repayment combinations for all two-person borrowing groups in the structural estimation sample by loan officer. 
Table 8: Are the loan officers with RD groups observably different?

\begin{tabular}{lllll} 
& $(1)$ & $(2)$ & $(3)$ & $(4)$ \\
\hline Length of loan (weeks) & -0.004 & 0.000 & -0.001 & 0.001 \\
& $(0.006)$ & $(0.002)$ & $(0.002)$ & $(0.001)$ \\
Interest rate & $-1.650^{*}$ & -0.383 & -0.344 & -0.305 \\
(annualized) & $(0.841)$ & $(0.421)$ & $(0.429)$ & $(0.453)$ \\
Group size & $-0.017^{*}$ & 0.001 & 0.001 & 0.002 \\
& $(0.009)$ & $(0.002)$ & $(0.002)$ & $(0.002)$ \\
Loan size (000s pesos) & $0.003^{* * *}$ & 0.001 & 0.001 & $0.001^{*}$ \\
& $(0.001)$ & $(0.000)$ & $(0.000)$ & $(0.001)$ \\
Borrower age & 0.000 & 0.001 & $0.000^{*}$ & 0.000 \\
& $(0.001)$ & $(0.000)$ & $(0.000)$ & $(0.000)$ \\
Borrower is male & 0.039 & -0.007 & -0.006 & -0.002 \\
& $(0.050)$ & $(0.007)$ & $(0.007)$ & $(0.006)$ \\
Borrower's tenure with & 0.000 & 0.000 & 0.000 & 0.000 \\
bank & $(0.000)$ & $(0.000)$ & $(0.000)$ & $(0.000)$ \\
\hline Branch Fixed Effect & No & Yes & Yes & Yes \\
Year Fixed Effect & No & No & Yes & Yes \\
Branch-year Fixed Effect & No & No & No & Yes \\
Dep.var. mean & 0.158 & 0.158 & 0.158 & 0.158 \\
R-squared & 0.100 & 0.593 & 0.596 & 0.619 \\
Observations & 22555 & 22555 & 22555 & 22555 \\
\hline
\end{tabular}

Notes: The dependent variable is an indicator variable equal to one if the loan officer oversaw a two-member borrowing group in which one member defaulted and one repaid. The sample comprises all loans overseen by loan officers who oversaw at least one two person borrowing group loan. Borrowing groups comprising two members are excluded for comparability with default results. Because the variables of interest are at the loan officer level, each observation is weighted by the number of two person borrowing groups the loan officer oversaw and the standard errors (reported in the parentheses) are clustered at the loan officer level. Stars indicate statistical significance: ${ }^{*} \mathrm{p}<.10 * * \mathrm{p}<.05 * * * \mathrm{p}<.01$. 